The Rise and Fall of Behaviorism

The Narrative and the Numbers

Michiel Braat, Jan Engelen, Ties van Gemert, and Sander Verhaegh ${ }^{1}$

Tilburg University

The history of twentieth-century American psychology is often depicted as a history of the rise and fall of behaviorism, the view that psychology should become "a purely objective experimental branch of natural science" (Watson, 1913, 248). Where early twentieth-century psychologists aimed to redefine their discipline as a science of behavior, the popularity of

${ }^{1}$ All authors contributed equally to this work (author names listed in alphabetical order). We would like to thank Nees Jan van Eck, members of the History of Behavior Analysis mailing list (especially Nicole L. Banks and François Tonneau), audiences at conferences at the University of Amsterdam, the CEU Institute for Advanced Study Budapest, and the Tilburg School of Humanities and Digital Sciences, and the anonymous referees of History of Psychology for their valuable comments and feedback. This research is funded by the Tilburg School of Humanities and Digital Sciences Research Traineeships Programme. In addition, Verhaegh's research is funded by The Netherlands Organisation for Scientific Research (grant 275-20-064). Correspondence concerning this article should be addressed to Jan Engelen (j.a.a.engelen@uvt.nl) and Sander Verhaegh (a.a.verhaegh@uvt.nl), Tilburg School of Humanities and Digital Sciences, Tilburg University, Warandelaan 2, 5037AB, Tilburg, The Netherlands.

(c) 2020, American Psychological Association. This paper is not the copy of record and may not exactly replicate the final, authoritative version of the article. Please do not copy or cite without authors' permission. The final article will be available, upon publication, via its DOI: $10.1037 /$ hop 0000146 
behaviorism declined from the late 1950s onwards, when psychologists, linguists, and computer scientists joined forces and developed empirical approaches to the study of mind and cognition. Although historians of science disagree about the theoretical and social factors that have contributed to the development of experimental psychology (Cohen-Cole, 2014; Greenwood, 2009; Leahey, 2001), there is a widespread consensus about the growing and declining influence of behaviorism in twentieth-century American psychology (DeGrandpré and Buskist, 2000; O’Donohue and Kitchener, 1999b; Staddon, 1990; Zuriff, 1985).

From a methodological perspective these claims are contentious. For wide-scope claims about the development of American psychology are rarely backed up by representative empirical data. Although nobody will deny that many of today's best-known behaviorists produced their most influential work between 1920 and 1960, it is unclear what proportion of American psychologists embraced a behavioristic conception of psychology both during and after the heydays of behaviorism. Similar worries can be raised about the historians' conclusions about developments internal to behaviorism. Although most scholars identify Watson, Hull, Tolman, and Skinner as the most influential (neo-)behaviorists, ${ }^{2}$ these claims are seldom supported by balanced empirical evidence. In general, it is unclear to what extent the list of psychologists that have been most extensively studied by historians of behaviorism forms a faithful representation of the scholars that actually influenced the development of behaviorism in the first half of the twentieth century.

${ }^{2}$ See, for example, Boakes (1984, 237), Smith (1986, 21-22) and Mills (2012, 104-108). Most historians paint a picture of the development of behaviorism in which first Watson and later Hull and Tolman offered the "dominant orientation in American departments of psychology until after the end of the Second War, when it was displaced by [Skinner's] radical behaviorism" (Greenwood, 2009, 477). 
The problem that wide-scope claims about the history of American psychology are rarely backed up by balanced empirical data is especially pressing because it seems likely that historians overestimate the influence of canonized schools and scholars (whether it is behaviorism in the 1930 s or cognitive psychology in the 1970s). Not only do historians tend to ignore psychologists who did not belong to any school (Green et al., 2013); in studying the histories of influential schools and scholars, historians also tend to limit themselves to the writings "of a few known authors that are transmitted from generation to generation [...] as the authors to read" (Betti et al., 2019, 296). More particularly, historical claims about the development of American psychology are often based on corpora that are (1) not clearly specified (which texts exactly did the historian study in arriving at their conclusions?); (2) very small (how many of the tens of thousands of texts produced by psychologists did the historian actually read?); and (3) not representative (how can the historian guarantee that the texts he/she studied form a representative sample of the total body of texts produced by psychologists?). Although in-depth text analyses and archive studies can provide historians with a first indication of the influence of a psychologist, a method, or a school of psychology, their conclusions will always be shaped by the texts and archives they choose to study.

In this paper, we aim to transcend the received view about the development of twentieth-century American psychology in two ways. First, we use advanced text analysis tools (e.g. bibliometric mapping, co-citation analysis, and co-occurrence analysis) to quantitatively analyze the metadata of 119.278 papers published in American psychology journals between 1920 and 1970. We analyze both the citations and the title terms of these papers and generate co-citation and co-occurrence networks for every consecutive decade between 1920 and 1970 in order to reconstruct the structure and development of mid-twentieth century American psychology. Second, we argue that the question whether behaviorism was the 'dominant' school of American psychology is historically misleading to begin with. Using the results of 
our bibliometric analyses, we argue that questions about the development of American psychology deserve more fine-grained answers.

This paper is organized as follows. After a brief outline of what might be called the received view about the history of behaviorism, we explain the main methodological challenges surrounding quantitative representations of the development of American psychology. Next, we describe our data and methods and provide an overview of our findings about the structure and development of American psychology between 1920 and 1970. Finally, we discuss the implications of our findings and argue that the standard story about the development of American psychology needs reappraising.

\section{Behaviorism: The Narrative}

Behaviorism is a complex of methodological, epistemological, and sometimes ontological assumptions about the foundations of psychology. Where psychology is traditionally defined as the study of mental phenomena, behaviorists typically argue that psychology should become a science of behavior. More specifically, most behaviorists agree that (1) psychology is or should become a branch of natural science, (2) that psychologists should study behavior instead of mental phenomena, and (3) that a science of behavior should be built exclusively on publicly available evidence (thereby dismissing the use of introspection in psychological research). Usually, behaviorists combine this view about the nature of psychology with a set of empirical assumptions - for instance, the assumption that the behavior of an organism is determined by the organism's reinforcement history. Outside these shared philosophical and empirical commitments, behaviorists also strongly disagree about a wide range of issues. Most importantly, they disagree about the domain for psychology (should a study of behavior include or exclude physiological variables?), the nature of the observation language (should behaviorists tolerate intensional descriptions or purposive language?), and 
the types of theoretical concepts allowed in the construction of behaviorist theories (are intervening variables or hypothetical constructs acceptable?).

Historians often distinguish between two types of behaviorism in psychology: methodological and radical behaviorism (Day, 1983; Mills, 2012; Moore, 1981). ${ }^{3}$ Methodological behaviorists view (1)-(3) as a set of methodological prescriptions; they do not believe that psychologists should say something about the ontological status of mental states. According to the methodological view, psychologists should aim to scientifically describe and explain behavior without referring to mental states, images, or processes. Radical behaviorists, on the other hand, deny that mental entities exist and argue that private events should be included in the analysis of behavior-i.e. that private events should be analyzed in terms of the same principles that have been used to study overt behavior (Day, 1983; Ringen, 1999; Skinner, 1974).

Although behaviorism is generally viewed as a distinctively American psychology, most historians recognize that its roots can be traced back to the work of the Russian objective psychologists or reflexologists (Boakes, 1984; Fuchs \& Miller, 2003; Hergenhahn, 2005). ${ }^{4}$ Ivan Sechenov, often credited as the founder of this school, worked on the (excitatory and inhibitory) mediational role of the cerebral cortex in reflex actions and extrapolated his findings to the concepts of psychology. In Reflexes of the Brain, Sechenov defended the view that every mental process is reducible to a physiological reflex: "only physiology holds the key to the

${ }^{3}$ We include the qualification "in psychology" because the present overview excludes the role behaviorist theories played outside psychology (e.g. philosophy, economics, and sociology). See, for example, Pooley and Solovey (2010) and Hauser (2015).

${ }^{4}$ In addition, historians generally recognize that behaviorism also affected the development of psychology outside the United States. See, for example, Ardilla (2009). 
scientific analysis of psychical phenomena" (1863/1965). Ivan Pavlov and Vladimir Bekhterev extended Sechenov's work by independently discovering the principles of classical conditioning. Indeed, Sechenov's call for an objective psychology seems to have played an important role in Pavlov's conclusion that his experimental results (dogs salivate in response to food stimuli at a distance) could be explained without positing 'psychic secretions' (Pavlov, 1923/1928, 39).

Textbooks generally describe the rise of behaviorism in American psychology as a distinctively Watsonian revolution (Todd, 1994). Indeed, Watson coined the term 'behaviorism' and played a substantial role in shaping the debate about objective psychology in his manifesto "Psychology as the Behaviorist Views It" (1913). Historians, however, offer a more nuanced view, showing that Watson's manifesto did not receive a lot of attention until the early 1920s (Coleman, 1988; Leahey, 2001; Samelson, 1981), when psychologists like W. S. Hunter, J. R. Kantor, Zing-Yan Kuo, Max Meyer, and A. P. Weiss started to defend distinctively behaviorist conceptions of psychology (Mills, 2012, 101). Historians also note that Watson was by no means the first to practice objective psychology in the American psychological community. Psychologists like E. L. Thorndike - who, despite discovering the law of effect, never identified as a behaviorist nor was viewed as such by his peers-William James, Jacques Loeb, and Knight Dunlap also used objective methods prior to 1913 (Burnham, 1968; O’Donnell, 1985; Todd, 1994).

In the late 1920s and early 1930s, the development of behaviorism entered a new phase. Influenced by P. W. Bridgman's call for operational definitions of theoretical concepts as well as the increasing popularity of logical positivism in the United States (Carroll, 2017; Walter, 1990; Verhaegh, ms.), behaviorists like Hull, Skinner, and Tolman started to develop more rigidly formulated variants of behaviorism; even though their deductive (Hull), inductive 
(Skinner), and purposive (Tolman) approaches strongly differed from each other. ${ }^{5}$ As a result, most historians distinguish between classical behaviorism and neobehaviorism in their views about the development of mid-twentieth century American psychology (Smith, 1986; DeGrandpré and Buskist, 2000; Parot, 2001).

After the Second World War, the popularity of behaviorism gradually declined. The waning influence of logical positivism, the pioneering work of G. A. Miller, Allen Newell, and Herbert Simon, developments in artificial intelligence and linguistics, the invention of the computer (and thereby the growing popularity of a computational perspective on cognition), as well as doubts about the scope of the behaviorist approach (Breland \& Breland, 1961; Chomsky, 1959; Lashley, 1951), contributed to what has been called the 'cognitive turn' in psychology. Where behaviorists had viewed psychology as science of behavior, the cognitivists developed new methods, approaches, and frameworks to study 'mental' processes in a strictly empirical fashion.

The nature of the cognitive turn has been highly disputed by historians of psychology. Some view the cognitive turn as a paradigmatically Kuhnian revolution (Baars, 1986; Gardner, 1985); others have suggested that that there is much continuity between cognitive psychology and methodological behaviorism (Leahey, 1992; Mandler, 2002), or even that the very notion of a 'cognitive turn' should be dismissed as an "origin myth", invented in the early 1970s by cognitive psychologists (Dember, 1974; Joynson, 1970) in order to foster a shared identity (Hobbs \& Chiesa, 2011). Still, historians generally agree that fewer and fewer psychologists identified as behaviorists from the late 1950s onwards.

\footnotetext{
${ }^{5}$ It should be noted that although Skinner's early work was heavily influenced by operationism and logical positivism, he started to dismiss these views about the nature of science from the mid-1940s onward. See Skinner (1945ab), Allen (1980), and Verhaegh (2019).
} 


\section{Behaviorism: The Numbers}

In this paper, we use bibliometric tools to study the development of American psychology between 1920 and 1970. Bibliometrics is a field of study that is characterized by the use of statistics for analyses of written publications such as articles or books. It has proven difficult to pin down exactly when and where the practice of bibliometric analysis began (Broadus, 1987; Hood \& Wilson, 2001) but historians often cite Eugene Garfield's development of the Science Citation Index in 1955 as the birth of modern bibliometrics (Garfield, 1963). As the available technologies improved during the 1960's and 1970's, bibliometrics developed from a limited field of study to a practice that uses a wide variety of data in order to accomplish a wide variety of goals (Martínez-Gómez, 2015; Liao, Zhang, Wang \& Wang, 2016). Nowadays, there are bibliometric analyses of disciplines as diverse as history, information science, and pharmacotherapy (Buchanan \& Hérubel, 1997; Lee, 2008; Thompson \& Walker, 2015).

One of the first bibliometric analyses that aimed to track the development of psychological schools was published in the late 1990s. Robins, Gosling, and Craik (1999) investigated the development of psychoanalysis, behaviorism, cognitive psychology, and neuroscience in the second half of the twentieth century in order to answer the question "[w]hich, if any, of the schools currently competing for intellectual influence and institutional power is most prominent" (p. 117, our emphasis). Their assessment of 'prominence' consisted of three indexes. First, the authors selected four journals (i.e. American Psychologist, Annual Review of Psychology, Psychological Bulletin and Psychological Review) which they considered to be representative of the entire field of psychology and assessed its contents using the PsycINFO database. Second, they examined the subject-matter of dissertations published between 1967 and 1994. Finally, the authors selected four of the top journals of each school (e.g. Journal of Experimental Analysis of Behavior for behaviorism) and developed a 
prominence index by "computing the total number of times per year the flagship publications cited articles published in each subdisciplinary field" (Robins et al., 1999). Their results suggested (1) that there is little interaction between psychoanalysis and the rest of psychology, (2) that the decreasing popularity of behaviorism gave rise to cognitive psychology, and (3) that cognitive psychology was still the most prominent school in the 1990s.

The main methodological challenge in studying the development of a discipline is to develop a reliable way to determine which authors and publications belong to which school. For most schools and approaches, it is extremely difficult to come up with a satisfying definition. Most definitions of behaviorism, for example, will be either (a) so strong that they exclude a whole range of authors that are typically perceived as representatives of the school or (b) so weak that they fail to exclude authors and publications from rivaling schools. This problem seems to be especially pressing for the classification of behaviorist psychologists and publications since historians have even debated the question to what extent cognitive psychology should be viewed as a variant of methodological behaviorism.

Robins et al. (1999) tried to circumvent such classification problems by using keywords. In determining the number of behaviorist publications, for example, they used the keywords reinforc\# and conditioning to represent behaviorism. They searched for these keywords in the article titles, abstracts, subject indices, and the keyword phrases listed by the authors. ${ }^{6}$ This keyword approach has proven influential. In recent years, many bibliometric studies in the historiography of psychology collected their data using keyword searches and/or

${ }^{6}$ For psychoanalysis, cognitive psychology and neuroscience, they used the keywords psychoanal\#, cognit\#, and neurosci\# or neuropsy\# respectively. They did not use the keywords behav\# or behavior\# because they deemed these words too generic. 
similar measurement techniques (e.g. Burman, Green \& Shanker, 2015; Guilera, Barrios \& Gómez-Benito, 2012; Liu \& Oakland, 2016; Schui \& Krampen, 2010). ${ }^{7}$

In the present study, however, we develop a different approach. Although we will study the occurrence of terms like reinforc\# and conditioning in article titles (more on this below), we refrain from using keyword analyses to study the development of American psychology between 1920 and 1970. Our reasons are threefold. First, many articles published between 1920 and 1970 do not have abstracts or author keywords. Our data contains titles and citation data for each of the 119,278 articles published in this period but this is too limited information to solely rely on a keyword analysis. After all, it is implausible that most or even a majority of the behaviorist papers will use terms like reinforc\# and conditioning in their titles. ${ }^{8}$ Second, we believe that keyword analyses should be generally used with caution because it is unclear to what extent they measure what they ought to measure. It is unclear, for example, what proportion of articles containing the term cognit\# will actually belong to the cognitivist school

${ }^{7}$ There has been a number of papers that looked at specific schools of psychology (Bala \& Gupta, 2010; Liu \& Oakland, 2016; Schui \& Krampen, 2010;), but so far there has been no bibliometric study that focuses on the rise and fall of behaviorism.

${ }^{8}$ In addition, the keywords provided by the indexing databases (e.g. PsycINFO; Web of Science) themselves are notoriously unreliable, especially when used to map developments before the 1960s. Burman (2018), for example, shows that throughout the development of the PsycINFO database, the meaning, content, and function of the "metadata" (e.g. keywords) has changed drastically, resulting in different classifications of articles over different time periods. In the 1960's, for example, the APA changed its manner of archiving and reporting index terms for both new and old articles to such an extent that all data before the 1960's "simply cannot be used to track trends" (Burman, 2018, 313). 
and, conversely, what proportion of cognitive psychology articles will contain the term cognit\#. Indeed, Robins et al. themselves admit that "keyword analyses do not detect all of the articles related to each school" and that they do not expect their "keywords to capture the full range of articles published in the flagship publications" (1999, p. 119n1). Third, we refrain from using keywords to classify authors and publications because most demarcation criteria based on keywords are too rigid. Not only do keyword classifications ignore conceptual changes-e.g. the fact that the meaning of concepts like reinforce\# and conditioning changed considerable due to especially Skinner's theoretical and conceptual innovations from the mid-1930s — most keyword analyses also do not allow for the possibility that (1) whether or not an author or a publication should be classified as behavioristic is a matter of degree and (2) that 'behaviorism' itself is a tremendously complex, multidimensional concept, such that it is well possible that authors or publications can be behavioristic in one sense but not in another.

Rather than employing unnecessarily inflexible, external standards to determine whether or not a particular author qualifies as a behaviorist, the present study will study the structure and development of American psychology by mapping the similarities between authors and concepts. In studying co-citation networks, for example, we do not use a strict demarcation criterion to determine whether or not a psychologist like J. R. Kantor, who developed an "interbehaviorist" approach in the early 1920s, should be classified as a 'real' behaviorist. Rather, we use citation data to study the way in which Kantor's work was perceived to be similar to the work of other psychologists by mapping the co-citations between Kantor and every author cited in American psychology journals between 1920 and $1970 .{ }^{9}$

${ }^{9}$ Co-citation is the frequency with which two documents are cited together. In order to be strongly co-cited, a large number of scholars must cite the two works together. As such, in 
Moreover, in studying co-citation networks, we also allow for conceptual changes over time by mapping the way in which historical actors perceived authors to be similar. It is possible, for example, that E. G. Boring's position was perceived to be antithetical to Watson's approach in the 1910 s and 1920 s but that the general perception changed when the former started developing operationist approaches to psychology from the mid-1930s onwards. If this is the case, it will be reflected by the fact that Boring occupies a different position in a network mapping co-citations from the 1920s than in a network mapping co-citations from the 1940s. Co-citation networks allow us to map these perceived similarities without us having to decide whether or not Boring from the 1930s onwards qualified as a (methodological) behaviorist.

In relying on co-citation networks, in sum, we deliberately do not rely on an external, theoretical definition of behaviorism; nor do we presuppose that whether or not a certain author or paper qualifies as behavioristic cannot be subject to change. Rather, we rely on a sociological characterization of behaviorism and assess which scholars were considered to be doing similar work by the psychological community at various points in time. The more often two authors are cited together in a particular decade, the closer to each other they will be situated in the co-citation network for that particular decade.

Apart from an analysis on the basis of author co-citation networks, we also employ term co-occurrence networks to describe the structure and development of American psychology. Term co-occurrence networks map the similarities between concepts without presupposing a strict criterion to determine whether or not concepts should be classified as behavioristic. A recent article by Flis and Van Eck (2018) describes a similar analysis of twentieth century psychology on the basis of 673,393 articles taken from 1,269 (psychology) journals focusing

measuring co-citation strength, one measures the degree of association as perceived by the population of citing authors (Small, 1976). 
on the time period 1950 to 1999 to test Cronbach's $(1957,1975)$ distinction between correlational and experimental psychology and to see whether there were significant changes in both content and amount of output. The authors generated six term maps and identified different clusters of terms representing different fields within psychology. The six term maps showed significant changes in both content and amount of input throughout the time period. In our analysis, we will build upon Flis and Van Eck's work and apply their method to our dataset. This second analysis will provide us with an additional method to assess the structure and development of American psychology. Because our co-occurrence analyses do not depend on citation data, it can be used as an independent check on the validity of our results in the first analysis. Furthermore, we show that some of the differences between the author and the term maps give rise to some interesting hypotheses about the development of twentieth-century American psychology.

\section{Data}

\section{Method}

The publication data were retrieved from Web of Science (WoS). The search was done using the Science Citation Index Expanded (SCIE) and the Social Science Citation Index (SSCI) of WoS, the only citation indices that include publications during the time span of interest. An advanced search query using the term "wc=(psychology) OR su=(psychology)" (where 'wc' is the WoS category tag and 'su' is the research area tag) was run with the three additional requirements that the results should be (1) articles, (2) published between 19201970, and (3) written in English. This query resulted in 119,429 articles from 246 different journals. These were downloaded with full record and cited references.

Next, the dataset was cleaned by removing all duplicate articles based on their following attributes: author, title, publication name, cited references and International Standard Serial Number. This led to a total of 119,278 articles in the dataset. Figure 1 shows the 25 
journals with the most articles in the dataset, which together contribute $52 \%$ of all data. The titles suggest that the major journals in the dataset were virtually all psychology journals. Because the data were not equally distributed over all the decades, the data were analyzed per decade. This ensures that the results are not skewed to the later decades, for which there are many more publications and citations. The number publications in the dataset per decade is shown in Figure 2. This figure shows that, except for 1941-1950, the number of publications grows exponentially every decade. ${ }^{10}$

Coverage of the data set. Concerns have been raised about the suitability of WoS for historical research. Its coverage of some areas of psychology has been characterized as uneven, containing fewer journals in the areas of organizational and clinical psychology than PsycINFO, while having more extensive coverage of neuroscience, methodology, and statistics journals (García-Pérez, 2010). Approximately 90\% of all documents in WoS originates from English-speaking countries (Orduña-Malea \& López-Cózar, 2014). While this may reflect a geographic or linguistic bias, this is not particularly troubling for our purposes, as we focus on developments within American psychology. Furthermore, 90\% of all documents in WoS are journal articles, which means that coverage of research monographs and conference communications is probably limited (López-Cózar, Orduña-Malea, \& Martín-Martín, 2018). This does not preclude citations of research monographs in journal articles from the database, but it might result in underrepresentation of fields where books are a vital aspect of the publication culture (García-Pérez, 2010).

10 Note that the period 1920-1930 consists of 11 years. This is because the overall dataset actually spans 71 years, not 70 . We chose to append this extra year to the earliest period to somewhat offset the sparsity of publications in that decade. 


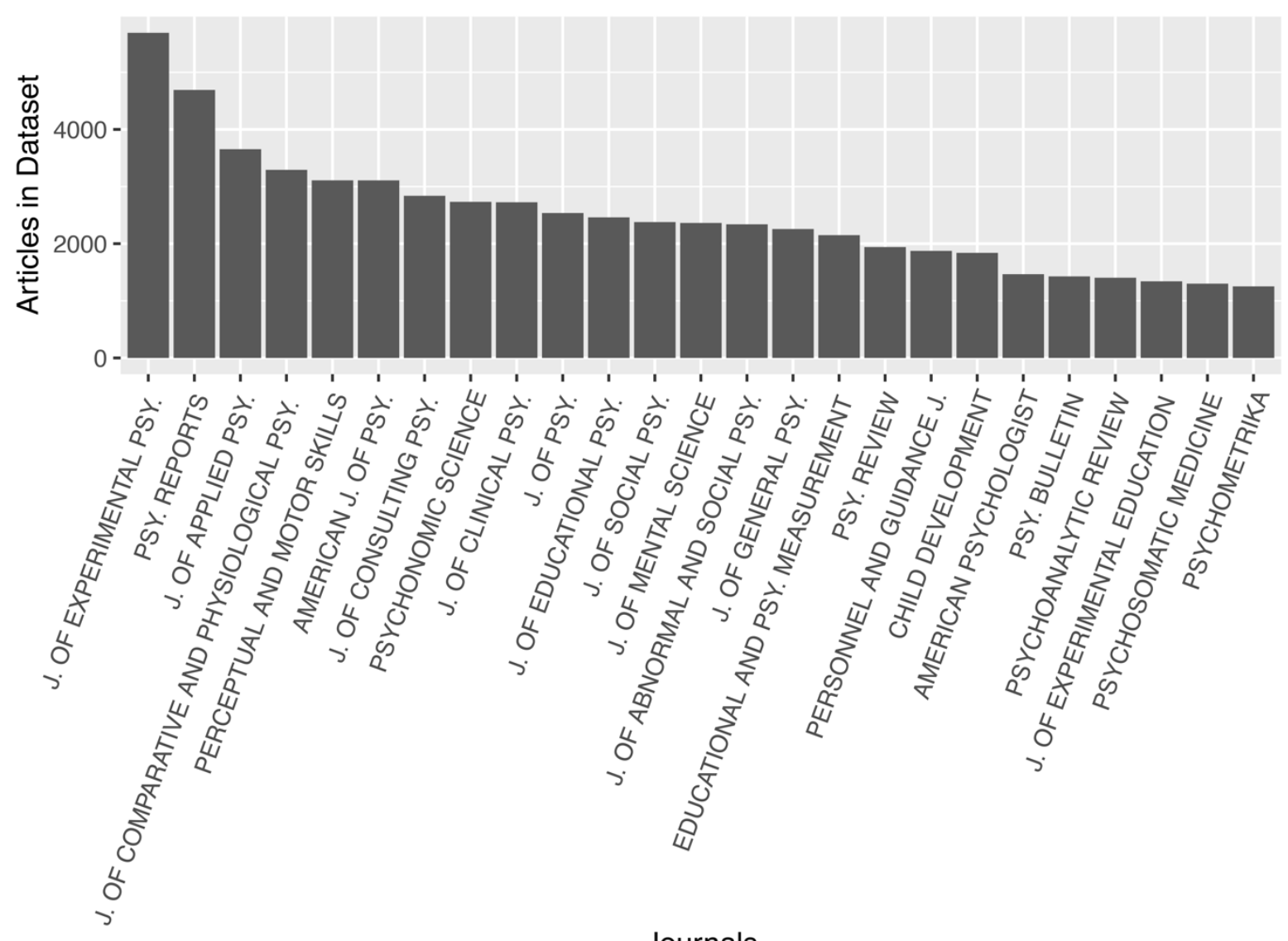

Figure 1. Number of articles per journal for the 25 journals with the most publications in the dataset.

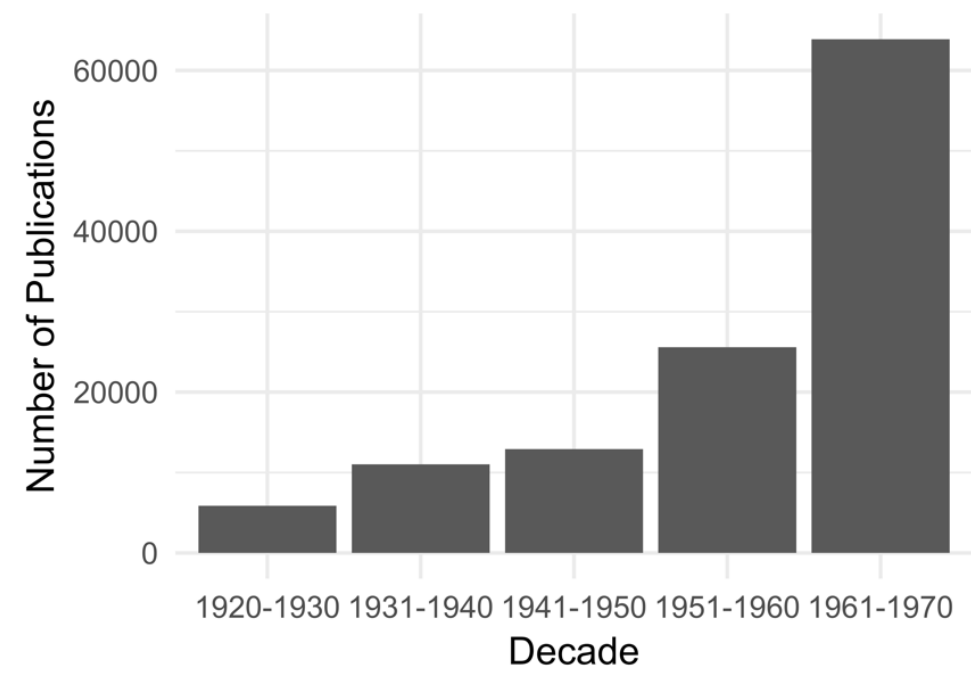

Figure 2. Number of publications in the dataset for each decade in 1920-1970. 
To assess the suitability of the SCIE and SSCI indexes in WoS for our research, we used a list of 15 journals that were regularly used by psychologists in the 1920 s and 1930 s. ${ }^{11}$ WoS nominally contained full records for 13 of these journals for the entire period of 1920 1970 (or from a later starting date if the journal was founded after 1920); two journals were included for a subset of that period. ${ }^{12}$ By comparison, PsycINFO contained records for nine of the 15 journals for the entire period of 1920-1970; two journals were not included and four journals were included for a subset of that period. ${ }^{13}$

11 These journals were: Acta Psychologica, American Journal of Psychology, American Psychologist, Contemporary Psychology, Journal of Comparative Psychology (and its successor Journal of Comparative and Physiological Psychology), Journal of Experimental Psychology (and its successors JEP: General, JEP: Human Perception and Performance, and JEP: Learning, Memory, and Cognition), Journal of General Psychology, Journal of the Experimental Analysis of Behavior, Proceedings of the American Academy of Arts and Sciences, Proceedings of the National Academy of Sciences, Psychological Bulletin, Psychological Review, Quarterly Journal of Experimental Psychology, Science, and The Psychological Record.

12 The two journals that were not completely included are Proceedings of the American Academy of Arts and Sciences and The Psychological Record.

${ }^{13}$ The two journals that were not included are Contemporary Psychology and Proceedings of the American Academy of Arts and Sciences; the four journal that were not completely included are Acta Psychologica; Proceedings of the National Academy of Sciences; Quarterly Journal of Experimental Psychology; Science). 
Our evaluation of SCIE and SSCI against our own list of sources suggests that WoS's coverage of major psychology journals is strong. Still, it is possible that coverage for other journals is less comprehensive, and that coverage at lower levels is spotty (e.g. missing issues for included journals, missing articles for included issues, and missing cited references for included articles). To assess in more detail whether the dataset provides full and accurate coverage of the literature from 1920 to 1970 , we selected two journals for each decade. The sampling procedure for the journals was as follows. First, for each decade, we ranked the journals in our dataset according to the ratio of cited references to published articles. The first journal was randomly sampled from the bottom 5\% of this ranking - thus, the set of journals containing fewer cited references than would be expected based on the average citation practice for that decade. The rationale was that WoS would be more likely to contain incomplete records (e.g. missing or incorrect entries in the cited references column) for these journals. The second journal was randomly sampled from the remaining $95 \%$ of journals for that decade.

For each of the ten selected journals, we checked the issues included in WoS for that decade against the issues as listed in the printed journal itself, or, if that was not available, against the table of contents on the publisher's website. Next, we randomly sampled one issue from each of these journals and checked the articles included in WoS against the articles as listed on the publisher's website. Finally, for five randomly selected articles from the issue, we checked the cited references in WoS against the cited references in the full text. The results of this procedure are displayed in Table 1.

For the journals with a low cited references-to-articles ratio, coverage in WoS varied somewhat between decades. FFor the journal selected for 1920-1930, one issue was not included, and two out of 20 articles were missing for the selected issue, without any apparent reason (i.e. the missing issue and articles appeared to be regular research publications). For the journal selected for 1951-1960, only four issues out of many were available, apparently because 
the journal is only indexed from 1960 onwards. For all other decades, WoS contained all issues. A number of articles for the selected issue were missing for 1961-1970. It should be noted, however, that these missing articles were not standard research reports, but rather a variety of very short (sometimes less than half a page) contributions. Finally, the cited references in WoS were complete for each article for each journal. This means that the low ratio of cited references to articles for these journals were not an artefact, but that these articles actually contained very few cited references. For the journals sampled from the remaining 95\% WoS included all issues, all articles, and all cited references. Thus, while WoS does not have perfect coverage for some journals, its overall coverage, especially for major psychology journals, was rather impressive and at least satisfactory for our purposes.

Citation data. From our datasets, the 200 most-cited authors per decade were extracted. These were needed for the generation of co-citation networks. The extraction of the top 200 most-cited authors per decade was done using VOSviewer (version 1.6.7), which extracts and counts the citations for each author. ${ }^{14}$ It is important to note that the cited articles do not have to be from the same decade as the publication data. Although William James died in 1910, for example, he is still one of the top 200 most-cited authors in the 1940s. We extracted a number of authors as close to 200 as possible (extracting more than 200 in case authors were tied for the rank of 200). Table 2 shows the number of authors per decade and the minimum required

${ }^{14}$ Some authors appear in the dataset under different names. These different names were normalised as much as possible, but in some cases it was not possible to determine which author a name refers to. For example, the dataset includes the authors 'D.G. Brown', 'J.S. Brown' and 'Brown'. It is then not possible to assign the citations of 'Brown' to either D.G. or J.S. Brown. In this case, 'Brown' was retained as a separate author. 
number of citations. This table shows that the minimum number of citations for an author to belong to the top 200 increases exponentially over the decades.

Table 1

Coverage of Web of Science for randomly selected journals in our dataset

\begin{tabular}{|c|c|c|c|c|c|}
\hline & Decade & Journal & $\begin{array}{l}\text { Issue } \\
\text { coverage } \\
\text { for decade }\end{array}$ & $\begin{array}{l}\text { Article } \\
\text { coverage } \\
\text { for issue }\end{array}$ & $\begin{array}{l}\text { Cited } \\
\text { reference } \\
\text { coverage }\end{array}$ \\
\hline \multirow{10}{*}{$\begin{array}{l}\text { Bottom } \\
5 \%\end{array}$} & 1920- & National Vocational & 1 missing & 1924-5, & complete \\
\hline & 1930 & Guidance Association & $(66 / 67)$ & 2 missing & \\
\hline & & Bulletin/Vocational & & $(18 / 20)$ & \\
\hline & & Guidance Magazine & & & \\
\hline & $\begin{array}{l}1931- \\
1940\end{array}$ & The Human Factor & $\begin{array}{l}\text { complete } \\
55 / 55^{*}\end{array}$ & $\begin{array}{l}\text { 1932-8, } \\
\text { complete } \\
(5 / 5)\end{array}$ & complete \\
\hline & $1941-$ & Occupations: The & complete & $1943-6$ & complete \\
\hline & 1950 & Vocational Guidance & $(81 / 80)^{* *}$ & complete & \\
\hline & & Magazine/Journal & & $(10 / 10)$ & \\
\hline & $\begin{array}{l}1951- \\
1960\end{array}$ & Canadian Psychologist & $\begin{array}{l}\text { only } 1960 \\
(4 / 40)\end{array}$ & $\begin{array}{l}\text { 1960-4, } \\
\text { complete } \\
(9 / 9)\end{array}$ & complete \\
\hline & $\begin{array}{l}1961- \\
1970\end{array}$ & Personnel Journal & $\begin{array}{l}\text { complete } \\
(113 / 113)\end{array}$ & $\begin{array}{l}1963-4, \\
13 \text { missing } \\
(5 / 18)^{* * *}\end{array}$ & complete \\
\hline \multirow{10}{*}{$\begin{array}{l}\text { Other } \\
95 \%\end{array}$} & 1920- & Journal of Educational & complete & 1921-0, & complete \\
\hline & 1930 & Psychology & $(11 / 11)$ & $\begin{array}{l}\text { complete } \\
(35 / 35)\end{array}$ & \\
\hline & $1931-$ & Journal of Applied & complete & 1933-4, & complete \\
\hline & 1940 & Psychology & $(60 / 60)$ & $\begin{array}{l}\text { complete } \\
(12 / 12)\end{array}$ & \\
\hline & $1941-$ & Journal of Applied & complete & 1946-4, & complete \\
\hline & 1950 & Psychology & $(60 / 60)$ & $\begin{array}{l}\text { complete } \\
(12 / 12)\end{array}$ & \\
\hline & $1951-$ & Educational and & complete & 1956-4, & complete \\
\hline & 1960 & Psychological & $(40 / 40)$ & complete & \\
\hline & & Measurement & & $(14 / 14)$ & \\
\hline & $\begin{array}{l}1961- \\
1970\end{array}$ & Psychological Review & $\begin{array}{l}\text { complete } \\
(58 / 58)\end{array}$ & $\begin{array}{l}\text { 1966-2, } \\
\text { complete } \\
(5 / 5)\end{array}$ & complete \\
\hline
\end{tabular}

*This journal was published from 1932 to 1937. It had 12 issues per year. A recurring issue is the annual report and statement of accounts (issue 3 in 1932 and 1933, issue 12 in 19341936). These annual reports are not included in WoS. 
**WoS has records for Issue 21(8), which was absent from the publisher's website.

***The contributions not present in WoS all seem to be from a category other than 'Original Article', e.g. commentaries (sometimes less than a column), book reviews, etc.

Table 2

Number of authors included in the dataset and their publication threshold per decade

\begin{tabular}{lll}
\hline Decade & Number of authors & Minimum number of citations \\
\hline $1920-1930$ & 201 & 24 \\
$1931-1940$ & 200 & 63 \\
$1941-1950$ & 202 & 74 \\
$1951-1960$ & 202 & 150 \\
$1961-1970$ & 200 & 342 \\
\hline
\end{tabular}

\section{Author co-citation networks}

For each decade we created an author co-citation network using the program VOSviewer. The association strength (Van Eck \& Waltman, 2009) between authors was used as the measure of similarity. For a given pair of authors, the association strength is proportional to the ratio between (1) the observed number of co-citations and (2) the expected number of co-citations if they would be statistically independent. Thus, authors with a large number of citations require a large number of co-citations to have a high association strength.

To map the association strengths for all pairs of authors onto a two-dimensional space, the VOSviewer software uses the VOS (visualization of similarities) method, which is similar to the more widely known technique of multidimensional scaling. In addition, VOSviewer uses this method to cluster the authors. In this case, a cluster is a group of authors with high mutual 
association strengths. The default clustering resolution of 1.0 was used in every network. ${ }^{15}$ For a more technical explanation of the clustering technique, see Waltman, Van Eck, and Noyons (2010).

\section{Term co-occurrence networks}

To create the term co-occurrence networks, we used the data from all 119,278 publications. Using the VOSviewer software, the titles ${ }^{16}$ were extracted from the publication data. The software then identified and extracted the longest possible noun phrases (or terms)

${ }^{15}$ While 1.0 is the default value, this does not in any way represent a 'neutral' value. The optimal clustering resolution may be different for each dataset. A common recommendation is to explore different values for each map and choose the one that yields the most satisfactory result. We believe this approach entails a risk of confirmation bias, however, because the result that is deemed most satisfactory is likely to be the result that matches the researcher's preconceptions. Still, we did explore different resolution values, but only to see whether the value of 1.0 represents a stable solution. We did not see appreciable differences for different parameter values (ranging from 0.8 to 1.2 ), unless reported otherwise.

${ }^{16}$ We relied on titles because full texts or even abstracts were available only for a subset of the articles. This requires that titles be representative of the contents of the articles for our conclusions to be valid. Given the strongly descriptive and matter-of-fact nature of many of the titles in the dataset, we believe the data go a long way toward meeting this assumption. Moreover, sporadic instances of titles containing terms that have little bearing on the contents of the article, or of titles lacking essential information regarding the object or method of study, only have a minor influence on the overall picture, since each network is based on thousands of titles. That said, an analysis based on full texts would most likely yield even richer, more nuanced conclusions. 
from the titles. Occurrences and co-occurrences of the terms were counted using a binary counting method, such that multiple occurrences of a term in a given title were counted as one occurrence. From the list of terms for each decade, the 100 most frequent terms were selected. ${ }^{17}$ We used a fixed number of terms to keep the networks comparable across decades. For the 100 most frequent terms per decade, association strengths were computed in the same way as for the authors. To create the term networks, VOSviewer uses the same mapping and clustering algorithm as for the author co-citation networks.

\section{Results}

\section{Co-citation networks}

Co-citation networks per decade. Table 2 provides an overview of the number of clusters generated by VOSviewer for each decade and the number of authors that are placed within these clusters. The clusters displayed in boldface are the clusters in which authors who are typically classified as behaviorists were most strongly represented. For each decade, we will describe the co-citation network in relation to the information presented in Table 3.

${ }^{17}$ VOSviewer also computes relevance scores for terms, such that frequent but uninteresting terms (e.g. 'study') may be filtered out. We refrained from using relevance scores as this would intermittently leave out terms like 'behavior', thereby possibly distorting the results by removing terms associated with behaviorism. The only term we excluded from the networks (1931-1940; 1941-1950) was 'iii', which was erroneously detected as a noun phrase. 
Table 3

The number of citations and authors for each cluster per decade

\begin{tabular}{llllllll}
\hline & & \multicolumn{5}{c}{ Cluster } \\
\cline { 3 - 7 } Decade & & $\mathbf{1}$ (red) & $\mathbf{2}$ (green) & $\mathbf{3}$ (blue) & $\mathbf{4}$ (yellow) & $\mathbf{5}$ (purple) & 6 (orange) \\
\hline $1920-$ & Citations & 3994 & 3149 & $\mathbf{2 2 8 0}$ & 2156 & 640 & \\
1930 & Authors & 64 & 51 & $\mathbf{3 8}$ & 36 & 12 & \\
$1931-$ & Citations & 10373 & 7562 & $\mathbf{5 3 6 3}$ & $\mathbf{3 0 0 0}$ & 1931 & \\
1940 & Authors & 75 & 63 & $\mathbf{3 4}$ & $\mathbf{1 6}$ & 12 & \\
$1941-$ & Citations & 10073 & $\mathbf{9 1 5 7}$ & 5892 & 4109 & 2385 & 835 \\
1950 & Authors & 67 & $\mathbf{5 6}$ & 33 & 24 & 15 & 7 \\
$1951-$ & Citations & 28915 & $\mathbf{1 8 6 9 6}$ & 14807 & 7848 & & \\
1960 & Authors & 86 & $\mathbf{5 5}$ & 35 & 26 & & \\
$1961-$ & Citations & 44779 & $\mathbf{3 5 5 4 9}$ & 28388 & 15656 & 6905 & \\
1970 & Authors & 69 & $\mathbf{5 5}$ & 46 & 17 & 13 & \\
\hline
\end{tabular}

1920-1930. For the decade 1920-1930, VOSviewer generated five clusters, shown in Figure 3. Cluster 3 (blue) contains most authors who are typically viewed as behaviorists by historians (e.g. the above-mentioned Watson, Tolman, Hunter, Kuo, and Weiss; but also H. C Warren, W. T. Heron, and H. Cason). ${ }^{18}$ The cluster also contains quite a few biologists and physiologists whose work was often appealed to by behaviorists (e.g. C. P. Stone, G. E. Coghill, W. T. Preyer, and W. J. Crozier). The most-cited authors in Cluster 3 are Watson (234 citations) and Hunter (178 citations).

If we interpret Cluster 3 as the 'behaviorist cluster', then behaviorist authors make up $19 \%$ of the top 201 most-cited authors of $1920-1930$, and also account for $19 \%$ of their citations. As such it is the third largest cluster. Cluster 1 is substantially larger, accounting for $32 \%$ of the most-cited authors and $33 \%$ of the citations between 1920 and 1930 . Cluster 1 does

${ }^{18}$ Not all names mentioned are visible in Figure 3, which only displays the most-cited names. 
not contain any author who is typically classified as a behaviorist ${ }^{19}$ and contains mostly psychologists who developed the field of mental testing and the closely related field of educational psychology (e.g. L. L. Thurstone, L. M. Terman, A. Binet, and C. E. Spearman, and G. M. Whipple). The most-cited authors of Cluster 1 are Thorndike (331 citations) and Terman (186 citations)..$^{20}$

Cluster 2 is also substantially larger than the 'behaviorist cluster' (25\% of the mostcited authors and $26 \%$ of the citations) and contains mostly psychologists connected to Gestalt psychology (e.g. K. Koffka, M. Wertheimer, and W. Köhler) and the structuralist school (e.g. E. B. Titchener and E. G. Boring). The most-cited authors of Cluster 2 are Titchener (372 citations), C. E. Seashore (141 citations), and Boring (131 citations). The most-cited authors overall are Titchener and Freud (359 citations). Freud's position in the co-citation network shows that there was little interaction between psychoanalysis and the rest of psychology (thereby contextualizing Robins, Gosling, and Craik's (1999) conclusion about the development of psychoanalysis after the Second World War).

19 The only exception is Clark Hull, who was mostly working on aptitude testing in the 1920s. It was only in the late 1920s that Hull started to develop a neobehavioristic explanation of higher mental processes.

${ }^{20}$ Despite the fact that he discovered the law of effect, Thorndike, as mentioned above, never identified as a behaviorist nor was viewed as such by his peers. Our analysis of the citation data underlying the co-citation network in Figure 3 confirms this view as it shows that especially Thorndike's Teacher's Word Book (1921) was frequently cited. 


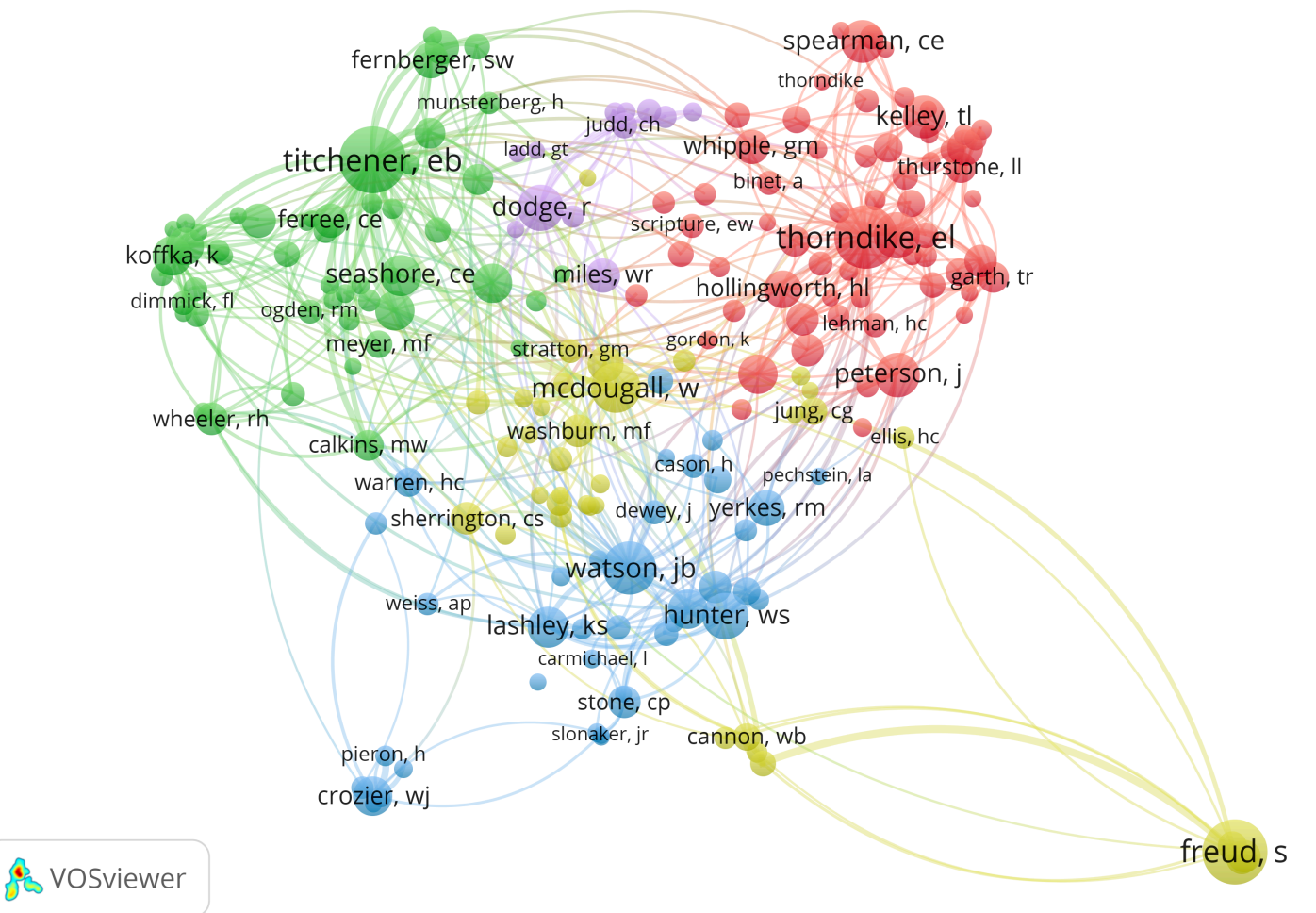

Figure 3. Co-citation network of the 201 most cited authors from the period 1920-1930.

1931-1940. For the decade 1931-1940, VOSviewer generated five clusters, shown in Figure 4. Cluster 3 (blue) contained the largest number of authors who are typically classified as behaviorists (e.g. Tolman, Hunter, Watson, Kuo, Spence, and Weiss), yet Cluster 4 (yellow) also contains a substantial share of authors who are typically viewed as behaviorists (e.g. Hull, Pavlov, Skinner, Razran, and Guthrie). ${ }^{21}$ If we view these clusters together as a 'behaviorist supercluster', then behaviorist authors make up 25\% of the top 200 cited authors of 1931-1940,

${ }^{21}$ Pavlov's more prominent presence in this network compared to that of 1920-1930, is due to the publication, in 1927, of the English translation of Conditioned reflexes: an investigation of the physiological activity of the cerebral cortex. 
and account for $30 \%$ of the citations. The most-cited authors included in clusters 3 and 4 are Hull (593 citations), K. S. Lashley (583 citations), and Tolman (419 citations).

It is tempting to attribute the appearance of two "behaviorist clusters' ${ }^{22}$ to the contemporaneous emergence of 'neobehaviorism', a movement generally associated with Skinner, Hull, and Tolman, and characterized by a stronger focus on formalizing the laws of behavior. Such an interpretation is not without problems, however: while Hull and Skinner are in the same cluster, Tolman is not. Still, it might be possible that the two clusters track a distinction between older and younger writers. Tolman (despite the fact that he would later be classified as a neobehaviorist), Watson, Spence, Kuo, and Muenzinger all started publishing well before $1930 \mathrm{and} /$ or had a background in comparative psychology, whereas the behaviorists in the yellow cluster started publishing later (Skinner, Razran), were translated into English later (Pavlov), or were doing little experimental work with animals in the 1920s (Hull, Guthrie). ${ }^{23}$

All the same, even combined, this 'behaviorist supercluster' does not constitute the largest cluster within psychology. Both Cluster 1 (red) and Cluster 2 (green) individually are larger than the two 'behaviorist clusters' combined. The authors in Cluster 1 account for $37 \%$ of the citations and the cluster contains mostly psychologists connected to the mental testing literature (Thurstone, Thorndike, and Spearman are the most-cited authors). Cluster 2 contains $32 \%$ of the most-cited authors and consists mostly of authors connected to Gestalt psychology

${ }^{22}$ To ensure this is not an artefact of the clustering resolution parameter value of 1.0, we tried coarser parameter values, until the number of clusters was reduced to four. Even in this map the two 'behaviorist clusters' remained separate (while the green and yellow clusters from Figure 4 had merged). Thus, these two subclusters most likely capture a real structure in the underlying data.

${ }^{23}$ We thank François Tonneau (personal correspondence) for this suggestion. 
and the structuralist school (the most-cited authors of the cluster are Köhler, L. E. Travis, and Koffka). Overall, Freud (868 citations) is the most-cited author in the 1930s.

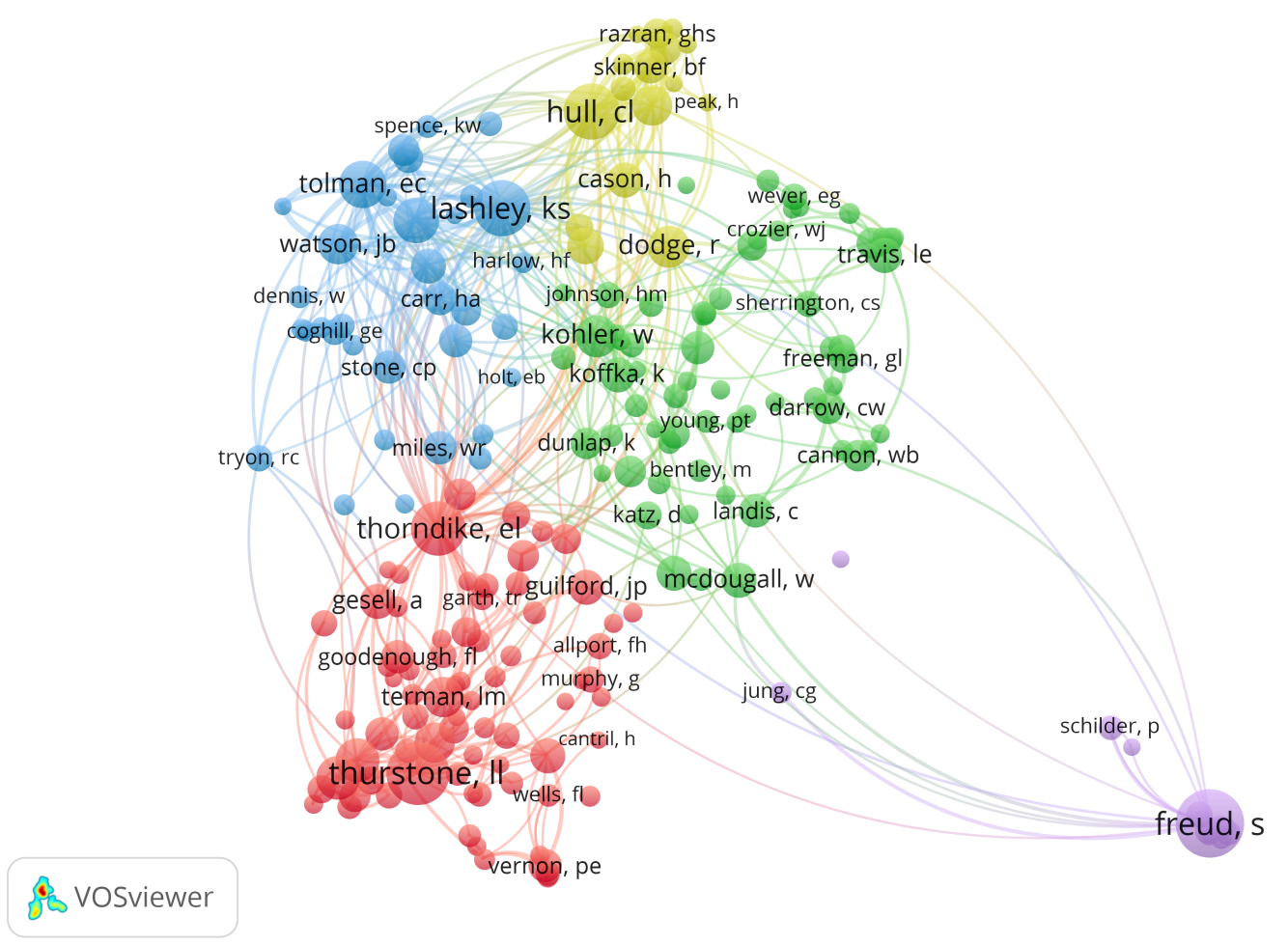

Figure 4. Co-citation network of the 200 most cited authors from the period 1931-1940.

1941-1950. For the decade 1941-1950, VOSviewer generated six clusters, shown in Figure 5. Virtually all authors who are typically classified as behaviorists (e.g. Hull, Tolman, Spence, Pavlov, Skinner, Hunter, Guthrie, Razran, Watson) are located in Cluster 2 (green). The most-cited members of this cluster are Hull (829 citations), Thorndike (400 citations), and Tolman (368 citations). If we interpret this as the 'behaviorist' cluster, then behaviorist authors make up $28 \%$ of the top 202 most-cited authors of 1931-1940 and account for $28 \%$ of their citations. As such, this cluster is only slightly smaller than Cluster 1 , which contains $33 \%$ of the most-cited authors and $31 \%$ of the citations. The most-cited authors in this cluster are Thurstone (696 citations), J. P. Guilford (546 citations), and C. Burt (425 citations), all 
connected to the study and testing of human intelligence. Overall, Freud (1612 citations) is, again, the most-cited author.

To nuance the suggestion that Cluster 2 can be identified as a 'behaviorist cluster', we should mention that the cluster also contains a large share of authors who are not typically classified as behaviorists. The cluster contains several Gestalt psychologists (e.g. Köhler and Koffka) and functionalists (e.g. R. S. Woodworth and W. James). ${ }^{24}$ A possible explanation for this composition is that the cluster does not so much represent a coherent behaviorist movement as a collection of authors who published on a common topic. This means that the cluster may not only contain proponents of behaviorism, but opponents too. Publications that are critical about behavioristic assumptions or findings by behaviorist authors may well end up being cocited with the publications they discuss. Conversely, some authors may be included in this cluster because they were critically cited in behavioristic publications.

${ }^{24}$ The cluster also contains operationist psychologists like E. G. Boring and S. S. Stevens but this only confirms the above-mentioned hypothesis that operationism was generally viewed as a variant of (methodological) behaviorism. 


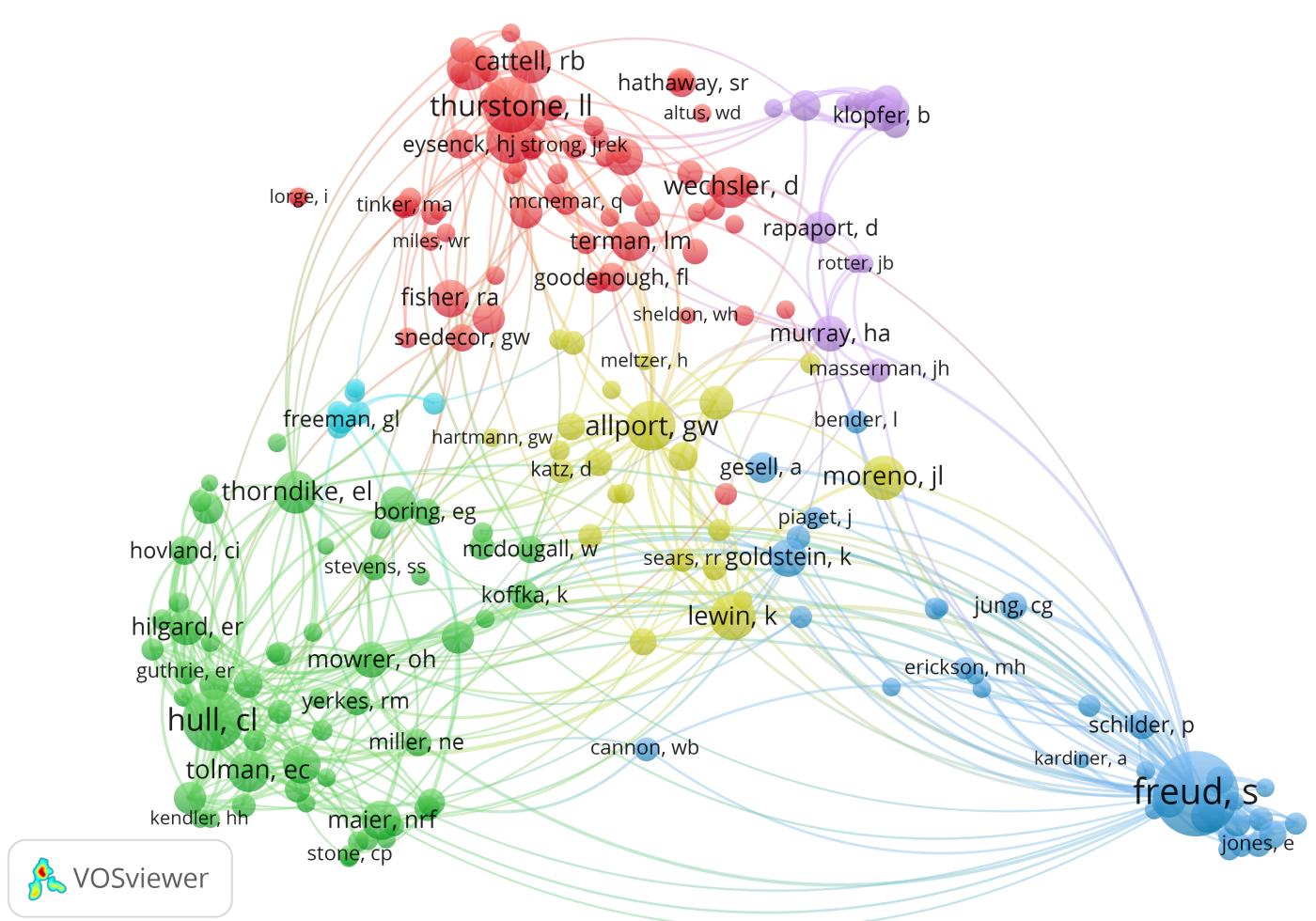

Figure 5. Co-citation network of the 202 most cited authors from the period 1941-1950.

1951-1960. For the decade 1951-1960, VOSviewer generated four clusters, shown in Figure 6. Again, virtually all authors who are typically classified as behaviorists (e.g. Hull, Spence, Skinner, Tolman, Estes, Pavlov, and Guthrie) are located in Cluster 2 (green). The most-cited authors of Cluster 2 are Hull (1538 citations) and Spence (1077 citations). Somewhat surprisingly, Skinner (600 citations) is not even represented in the top-5 most-cited authors of Cluster 2, despite the received view that Skinner came to dominate behaviorist research after the Second World War (footnote 2 above). If we interpret Cluster 2 as the 'behaviorist' cluster, then behaviorist authors make up 27\% of the top 202 most-cited authors and account for $27 \%$ of their citations. Cluster 1 is substantially larger, accounting for $43 \%$ of the most-cited authors and $41 \%$ of the citations between 1951 and 1960 . Cluster 1 does not contain any author who is typically classified as a behaviorist. The most-cited authors of 
Cluster 1 are R. B. Cattell (1264 citations), Guilford (1191 citations), and H. J. Eysenck (1167 citations).

The increasing gap between Clusters 1 and 2, compared to the co-citation network for the period 1941-1950, is explained by the fact that the Gestalt psychologists, the functionalists, and the operationist psychologists (Koffka, Köhler, Wertheimer, James, Woodworth, Boring, and Stevens) are now located in a separate cluster (Cluster 4, yellow). In general, the structure of the map shows a greater dispersion between clusters in comparison to the first two decades. Most of the 'behaviorist' cluster is located at the bottom left corner of the map, more remote from other clusters than in 1941-1950. The density of connections within this cluster and the relative sparsity of connections to other clusters suggest that behaviorism, while sustaining a substantial number of citations and authors, started occupying a slightly more peripheral position within American psychology.

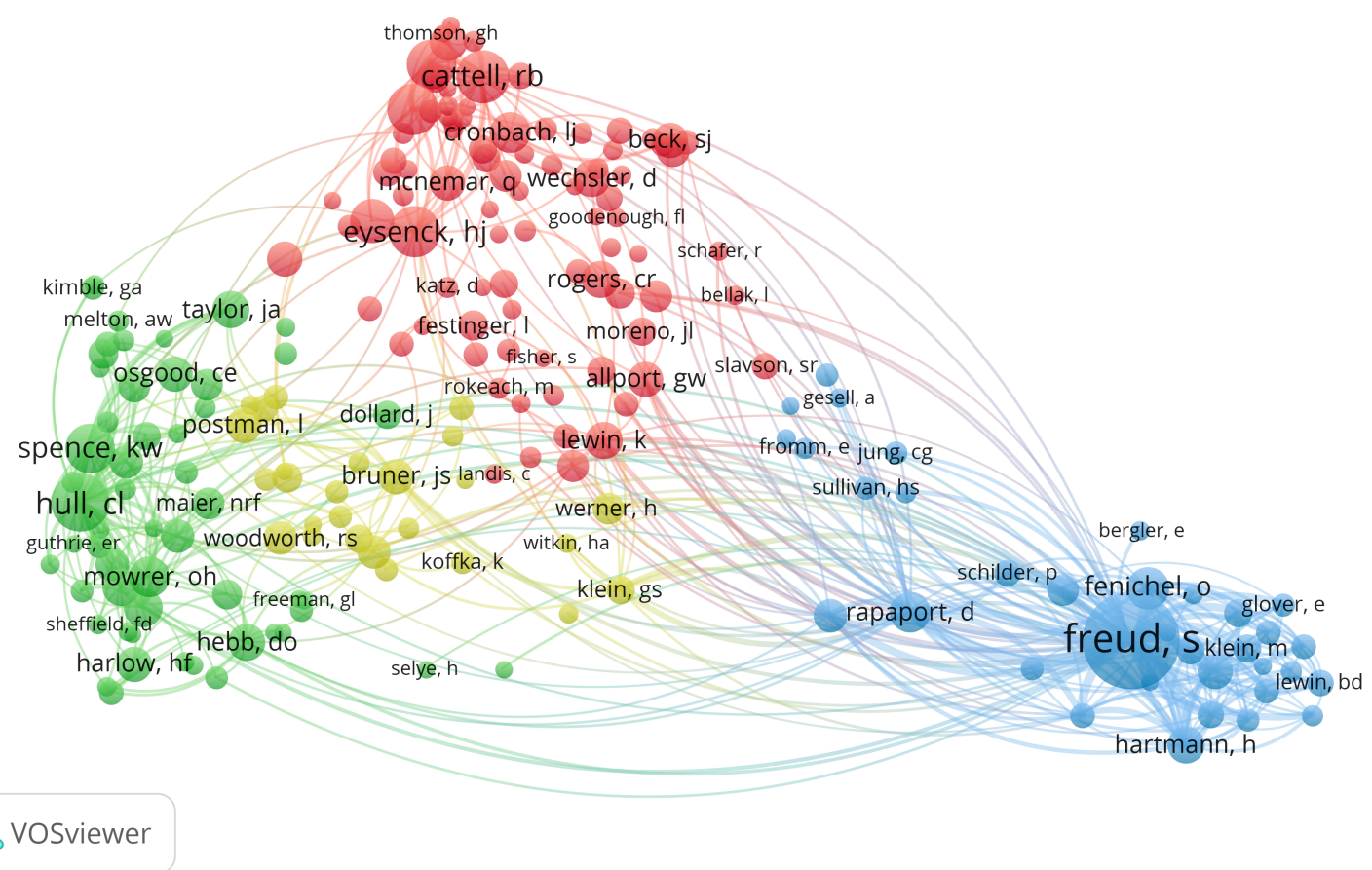

Figure 6. Co-citation network of the 202 most cited authors from the period 1951-1960. 
1961-1970. For the decade 1961-1970, VOSviewer generated five clusters, shown in Figure 7. Again, virtually all authors typically classified as behaviorists are located in Cluster 2 (green). The most-cited author is Spence (1603 citations); Skinner is still not included in the top 5 of most-cited authors in his cluster. If we interpret Cluster 2 as the behaviorist cluster, it remains the second-largest cluster with $28 \%$ of the most-cited authors and $27 \%$ of the citations. Cluster 1 is substantially larger, with $35 \%$ of the most-cited authors. Its most-cited authors are Eysenck (2348 citations), Cattell (2125 citations), and A. L Edwards (2048 citations). Freud (6290 citations) remains the most-cited author overall.

Notably, cluster 3 (blue) represents the emerging field of cognitive psychology, including authors such as G. A. Miller, N. Chomsky, G. H. Bower, and B. J. Underwood. Although this cluster still appears to be slightly smaller than the 'behaviorist' cluster (23\% vs. $28 \%$ of the most-cited authors; $22 \%$ vs. $27 \%$ of the total citations), it should be noted that Cluster 2 also contains a few cognitive psychologists and developmental psychologists (e.g. J. S. Bruner and J. Piaget) who are not typically classified as behaviorists.

Compared to the previous two decades, the 'behaviorist cluster' occupies a more central position on the map. This may partly be explained by the relation between behaviorism and cognitive psychology: in both subfields, the same phenomena (e.g. memory, learning) are studied, albeit from a different set of epistemological and methodological assumptions. One of the catalysts of the 'cognitive turn' was a perceived inadequacy of behaviorism to satisfactorily explain these phenomena. It is therefore not surprising to find many co-citations between these clusters. The publications concern similar subject matter and authors affiliated with the cognitive revolution often defined their positions relative to behaviorism. 


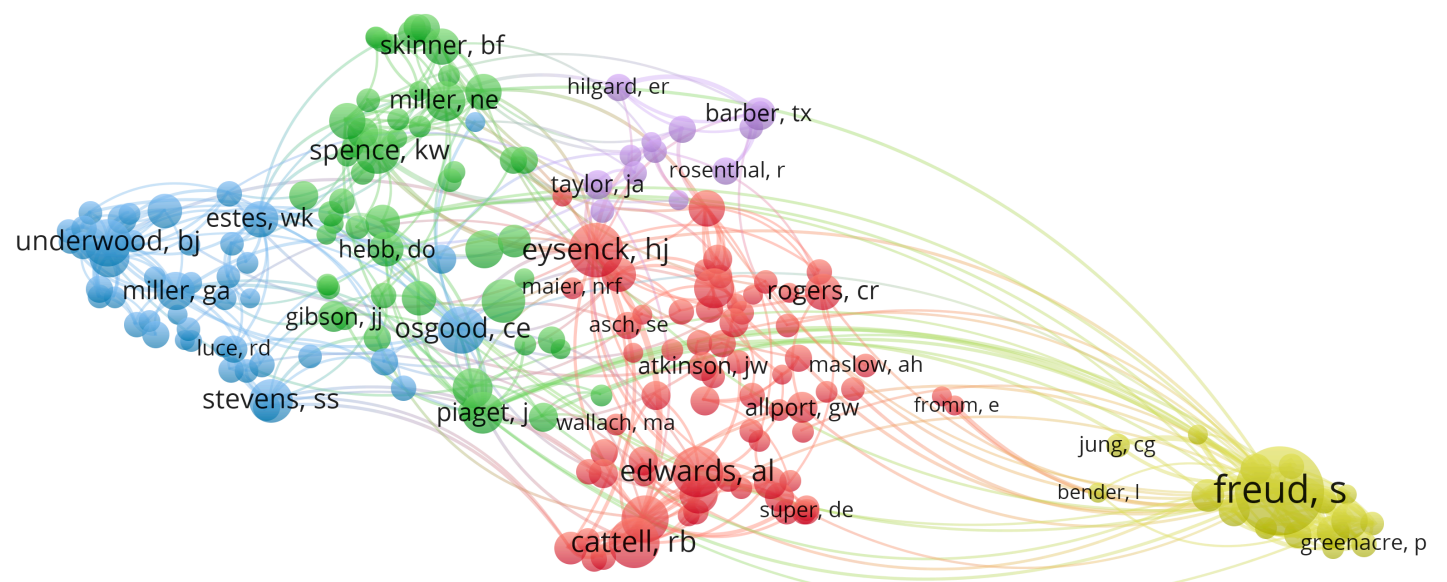

\& VOSviewer

Figure 7. Co-citation network of the 200 most cited authors from the period 1961-1970.

Summary of the co-citation networks per decade. In none of the decades that we analyzed did authors who are typically classified as behaviorists belong to the most prominent (combination of) clusters. This runs counter to the view that psychology was dominated by behaviorism in this part of the $20^{\text {th }}$ century. Even on a very catholic definition of behaviorism—combining the citations of all the clusters that contain authors who are typically classified as behaviorists - the proportion of behaviorists was never larger than $28 \%$ of the most-cited authors in a particular decade. ${ }^{25}$ Importantly, in none of the decades that we studied

${ }^{25}$ We call this a very catholic definition of behaviorism because we have shown that these 'behaviorist clusters' regularly also contained authors who are typically classified as Gestalt 
did the largest cluster contain authors who are typically classified as behaviorists. Moreover, our analysis also rules out an interpretation in which behaviorism may have been a small movement in an absolute sense, but larger than any other cluster in an otherwise disorganized field. In all decades, measurement of personality and mental abilities (championed by authors such as Cattell, Eysenck, Thurstone, Guilford, Burt, and Edwards) seems to be the main preoccupation of the field. Moreover, in the 1920s and 1930s, the clusters that appear to consist predominantly of Gestalt psychologists (Köhler, Koffka, Lewin) generated more citations than behaviorism.

On the other hand, our co-citation analyses also show that the influence of behaviorism did not dramatically decline after the Second World War either (at least up until 1970). In the 1960s, the behaviorist cluster still made up 28 percent of the field, more or less the same percentage as in the 1940s and 1950s. Absolutely speaking, the behaviorist cluster(s) even doubled in size almost every decade (except for the 1940s), growing from 8363 citations in the 1930 s, to 18696 citations in the 1950 s, to 35539 citations in the 1960 s. These results suggest not only that the share of citations to behaviorist papers remained stable between 1940 and 1970, but also that the absolute number of citations to the most important behaviorists quadrupled in the same period.

\section{Term co-occurrence networks}

1920-1930. For the decade 1920-1930, VOSviewer generated seven clusters, which are shown in Figure 8 . The aqua cluster contains terms $(n=9)$ that are typically associated with behaviorist research, such as 'behavior', 'white rat', and 'maze', while no such words occur in

psychologists, operationists, functional psychologists, developmental psychologists, and even cognitive psychologists. 
other clusters. The other clusters roughly correspond to areas such as clinical (yellow), educational (orange), and perceptual psychology (blue). The largest cluster (red) seems to contain mostly general terms, such as 'psychology', 'theory', and 'study'.

There is no clear spatial separation between the 'behaviorist' cluster and some of the other clusters; in fact, it falls almost completely within the boundaries of the larger green and purple clusters. Thus, it seems that this clustering is somewhat forced onto the data and that a given term's cluster membership does not imply it does not co-occur with terms from other clusters. Indeed, if we decrease the clustering resolution from 1.0 to 0.8 , then the 'behaviorist' cluster merges with the blue cluster (which still intersects the green cluster). This new cluster ( $\mathrm{n}=24)$ may best be described as 'experimental psychology' (containing terms such as 'experiment', 'perception', and 'memory').

All in all, the term co-occurrence map for this decade shows that a behaviorist vocabulary can already be distinguished in the publications, but also that the different clusters tend to be quite similar to one another, at least when compared to later decades.

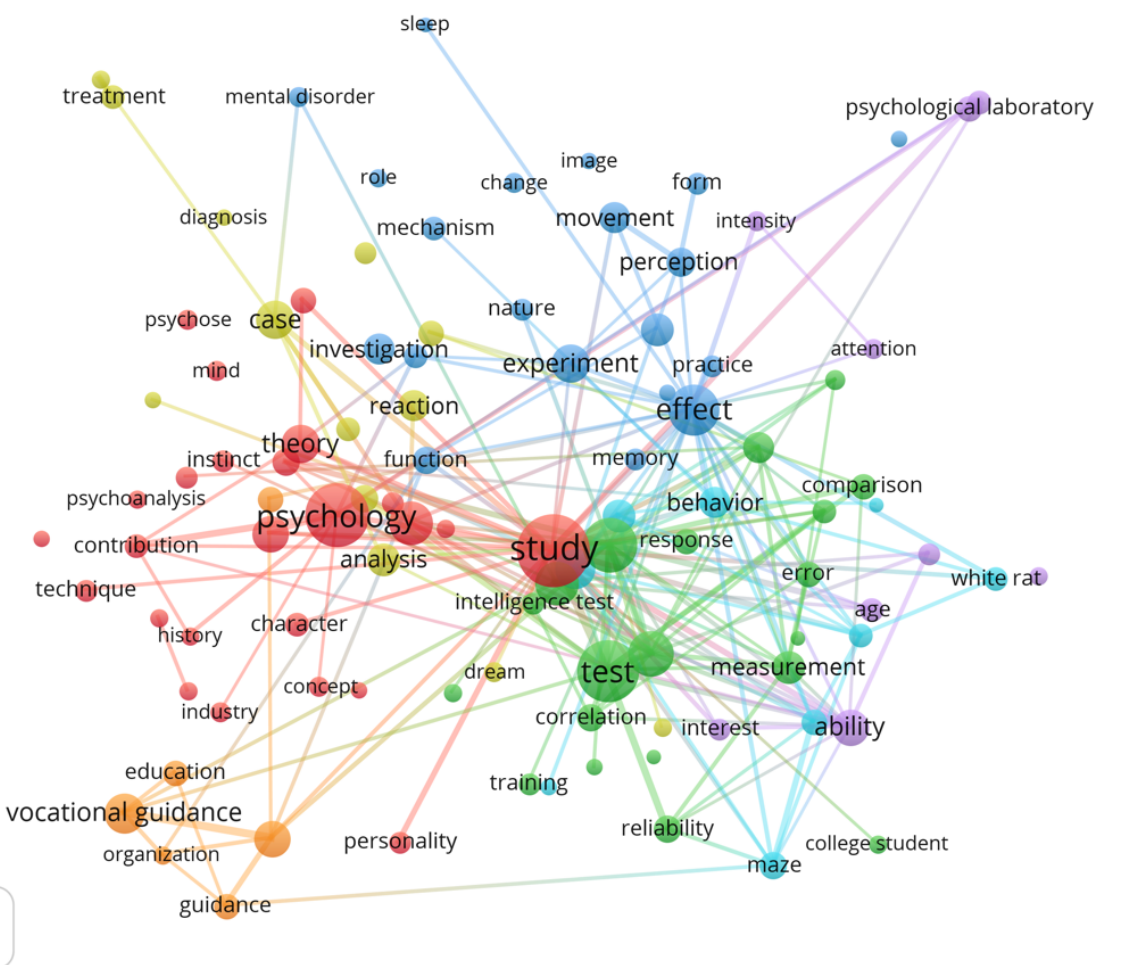


Figure 8. Term co-occurrence network for 1920-1930.

1931-1940. For the decade 1931-1940, VOSviewer generated six clusters, which are shown in Figure 9. Terms typically associated with behaviorist research ('behavior', 'learning', 'discrimination') are included in the red cluster $(n=27)$, which may best be described as representing experimental psychology. If we set the clustering parameter to a minimally finer value (1.0 to 1.01 ), this cluster breaks down into several subclusters, of which one remaining subcluster $(\mathrm{n}=12)$ consists exclusively of terms one would expect in behaviorist research, and a few typical behaviorist terms ('conditioning', 'reflex') located in a larger adjacent cluster.

Compared to the network for 1920-1930, the cluster with behaviorist terms is larger and more clearly separated from the other clusters. Looking ahead at the maps that will follow, we might see here the start of a bifurcation that will be most apparent from the 1950s onwards: correlational psychology on the left and experimental psychology on the right (for a discussion on how to characterize these two superclusters, see Flis and Van Eck, 2018). 


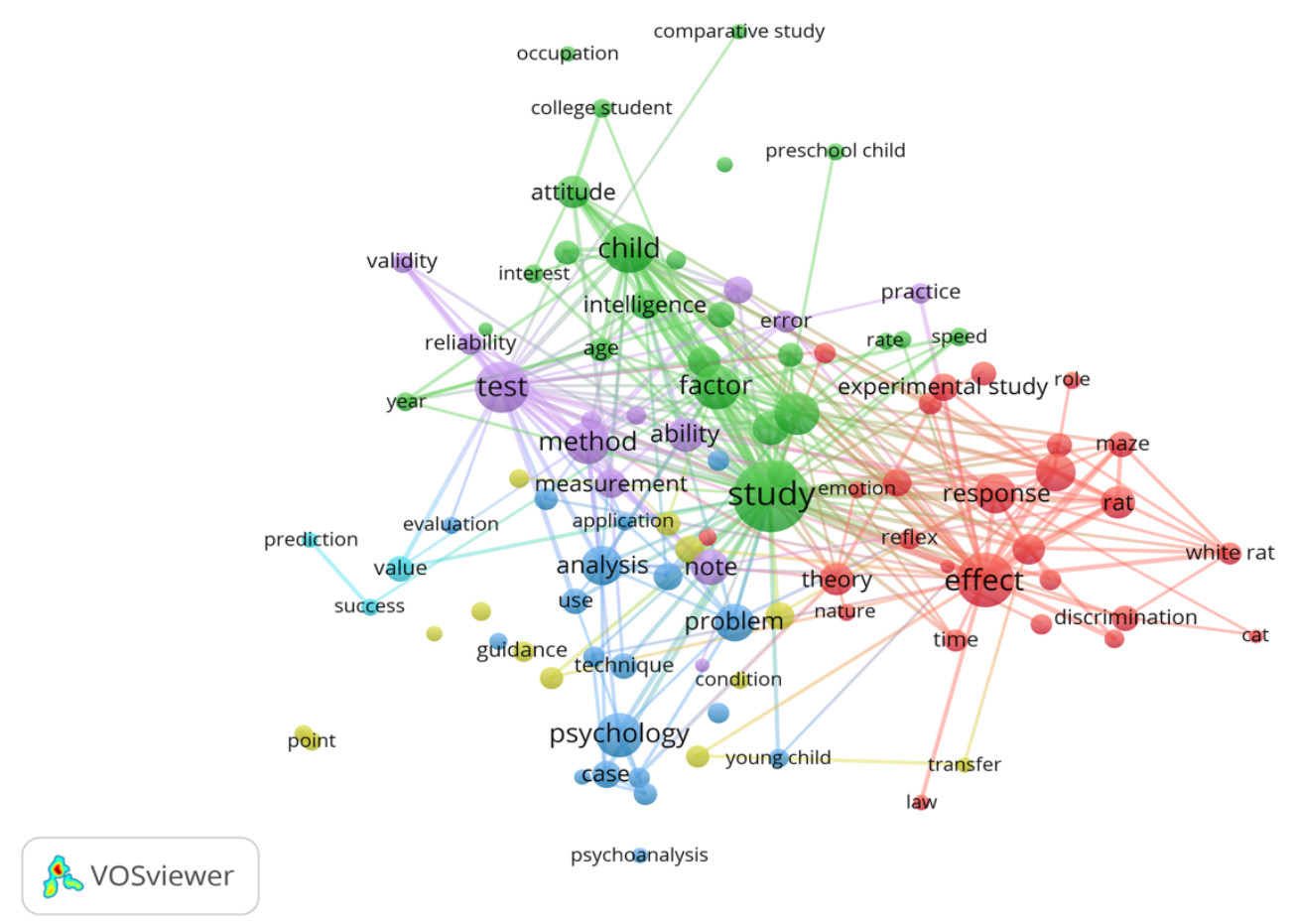

Figure 9. Term co-occurrence network for 1931-1940.

1941-1950. For the decade 1941-1950, VOSviewer generated six clusters, which are shown in Figure 10. The yellow cluster $(n=15)$ contains terms typically associated with behaviorist research, ('behavior', 'discrimination', 'rat'), but also terms that have a wider usage in experimental psychology ('effect', 'influence', 'degree'). Most of this cluster is clearly separated from the other clusters in the map, although one term ('study') intersects with other clusters. Compared to the network of 1931-1940, all terms that typically associated with behaviorist research are located within the same cluster. The 'behaviorist' cluster contains more terms, including some novel terms ('motivation', 'function' and 'response'). This reflects the growing popularity of terms typically associated with behaviorism. At the same time, a handful of its terms are located at the edge of the map, indicating that these terms have a relatively weak association with other terms in the map. 
The other clusters invite straightforward interpretations too. The purple cluster reflects clinical psychology ('therapy', 'case', 'treatment'). The blue and green clusters contain terms relating to mental testing and the measurement of personality ('personality', 'test', 'prediction') and aptitude ('child', 'ability', 'comparison'), respectively. The red cluster seems to have a mixed composition, consisting chiefly of general psychological terms ('psychology', 'theory', 'research'), but also psychoanalytical ('dream') and organizational terms ('work', 'vocational guidance'). ${ }^{26}$

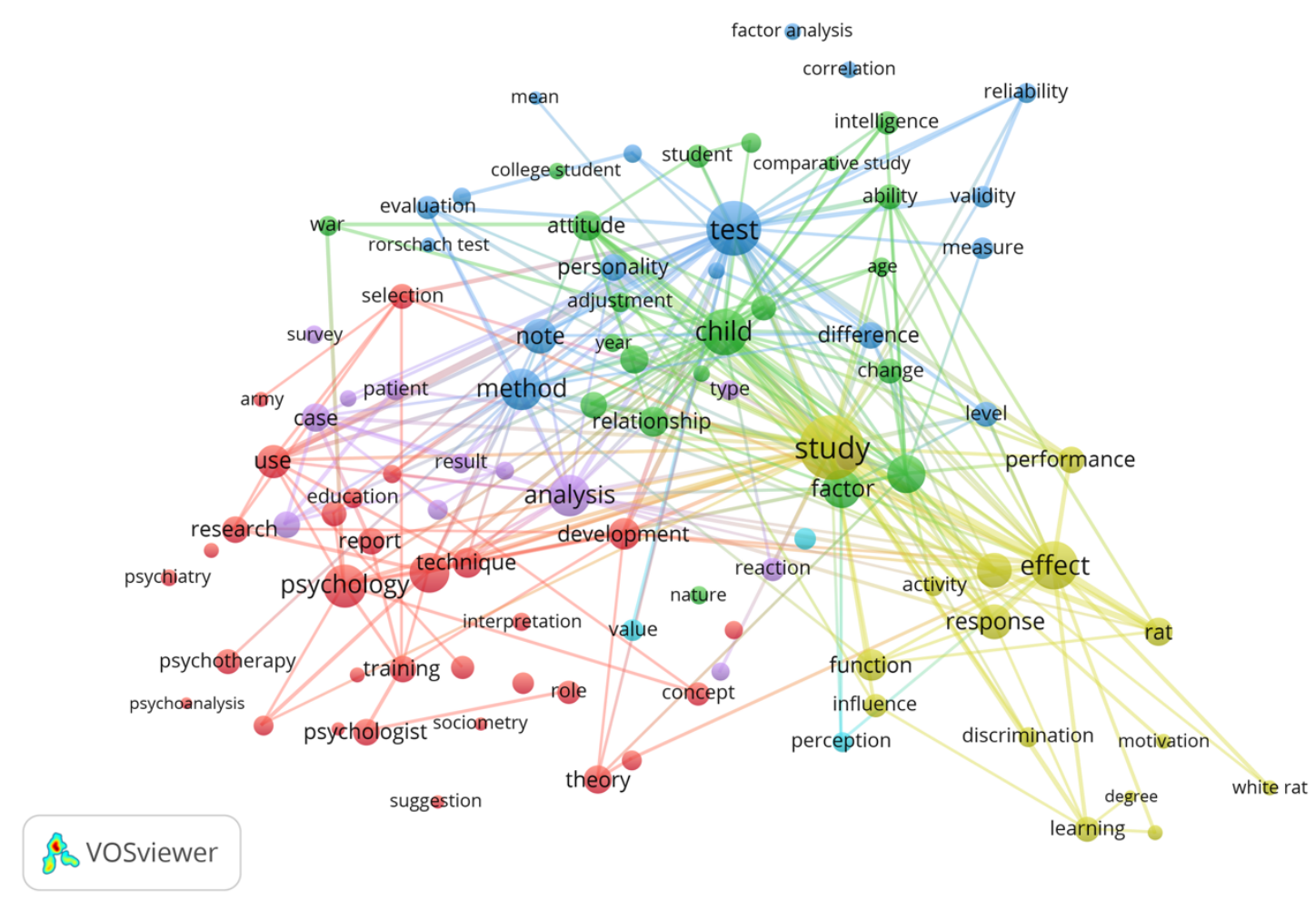

Figure 10. Term co-occurrence network for 1941-1950.

1951-1960. For the decade 1951-1960, VOSviewer generated four clusters, which are shown in Figure 11. Typical behaviorist terms ('reinforcement', 'learning', 'extinction') appear in the blue cluster $(\mathrm{n}=23)$. The blue cluster also contains terms that can take on specific

${ }^{26}$ Not all these terms are visible in Figure 10 due to its resolution. 
behaviorist meanings, but have a more general usage too ('effect', 'function', 'response'). These general terms are located at the left side of the cluster, near the center of the map.

Compared to the network of 1941-1950, the 'behaviorist' cluster has again increased in size. This is in line with a more general trend toward fewer clusters, which, because of the fixed number of terms in each network, must also be larger. Clinical psychology no longer has its own cluster (clinical terms are now subsumed under the red cluster) and the clusters for personality and aptitude testing have merged into one large cluster (the green cluster).

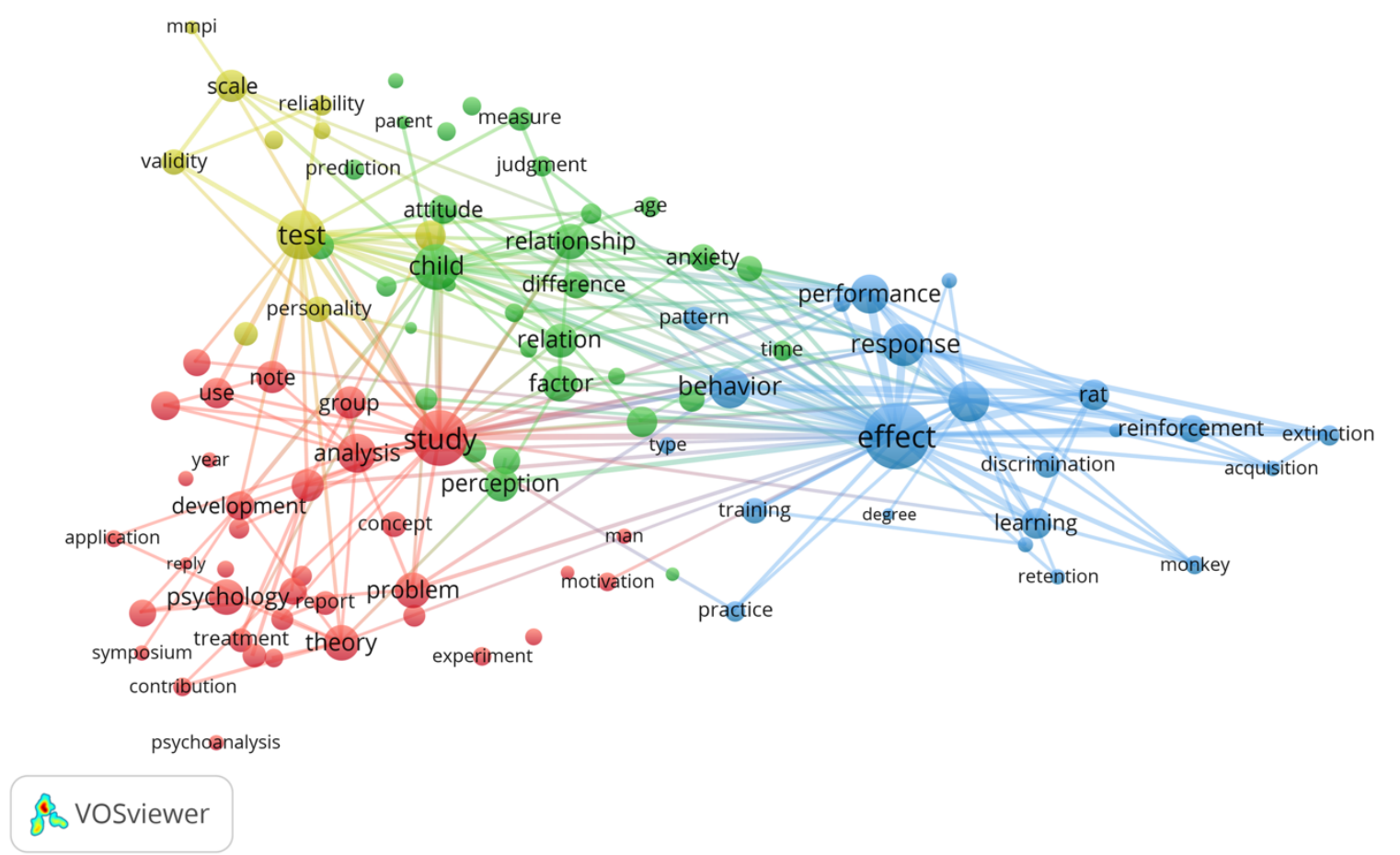

Figure 11. Term co-occurrence network for 1951-1960.

1961-1970. For the decade 1961-1970, VOSviewer generated four clusters, which are shown in Figure 12. Typical behaviorist terms $(n=21)$ appear in the blue cluster. As in the previous decade, this cluster contains both terms that are highly specific to behaviorism ('reinforcement', 'extinction', 'reward', 'resistance') and terms that are also used outside of 
behaviorist contexts ('effect', 'function', 'response'). The latter set of terms is again located near the center of the map. Compared to 1951-1960, the number of behaviorist terms remains more or less constant. The yellow cluster contains several novel terms that reflect the emergence of cognitive psychology ('short term memory', 'recall', 'information').

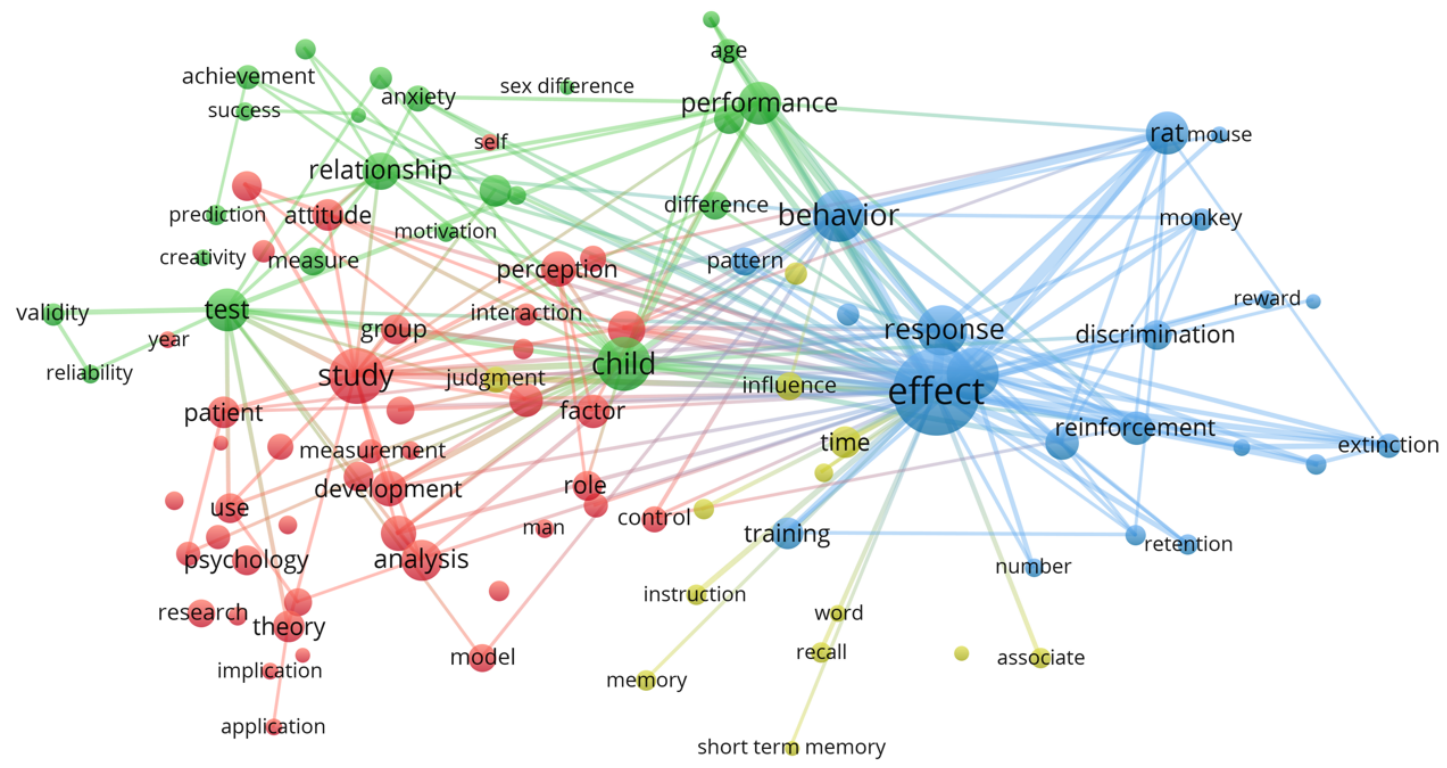

\section{VOSviewer}

Figure 12. Term co-occurrence network for 1961-1970.

Summary of the term co-occurrence networks per decade. When we track the development of the term co-occurrence networks across the time period of 1920-1970, we can draw a number of conclusions. First, the networks appear to develop a more orderly structure over time, with smaller numbers of clusters (from seven to four) and less spatial overlap between clusters. This might well reflect the development of the overall field of psychology, in which several subdisciplines became integrated throughout the 20th century. Second, the share of terms typically associated with behaviorist research in the top 100 title words for each decade increases until at least the 1950s. This might be because the behaviorist vocabulary 
grew over these decades, such that new terms were coined, or rather, that existing terms were increasingly used in a specific behaviorist sense. Alternatively, certain terms, which were already in use earlier, could have become more frequent in titles and entered the top 100 at the cost of other terms. In both scenarios, a plausible explanation is that more publications appeared that can be characterized as behavioristic.

There are some interesting commonalities and differences between the author and term networks. Both series of maps are similar in that they display growing popularity of authors and concepts typically associated with behaviorism after the $1920 \mathrm{~s}$, but whereas the size of the behaviorist clusters remained stable in the author networks, the popularity of the behaviorist vocabulary continues to grow (and plateaus in the 1960s). We see two potential explanations. First, it is possible that a lot of behaviorist work was published after the 1940s, but that this was work generated relatively few citations in the field of psychology as a whole. Second, some terms in the 'behaviorist clusters' might have been used in work that scholars would not commonly classify as behaviorist, but that did build on methods developed by paradigmatic behaviorists, or was concerned with phenomena (e.g. behavior, learning) that were originally put on the agenda by paradigmatic behaviorists. In that scenario, what these networks might reflect is the success of behaviorists in setting the direction of at least a part of psychological inquiry (cf. Roediger, 2004).

The combination of the term co-occurrence networks and author co-citation networks could also shed light on another discussion. From the term co-occurrence networks alone, one might get the impression that psychology, at least from the 1950s onward, consists of two subdisciplines, characterized as experimental psychology and correlational psychology (Flis \& Van Eck, 2018), that co-exist with very little interaction. The author co-citation analyses, however, suggest a different interpretation. If both subdisciplines were truly separated, one would expect to see this reflected in the author co-citation networks, such that authors should 
mostly cite work from other authors in their own area. This was not the case. The different overall structure of the author co-citation networks, then, might reflect the simple fact that authors do regularly cite work from those working in a different disciplines. For example, it is common for experimental studies on the influence of one variable on another to refer to studies showing correlational evidence for a link between these variables. The co-citation map is also consistent with a more radical re-interpretation, however: the term co-occurrence maps might not relate to any underlying division in the field, but rather to the fact that different types of studies use their own vocabulary. As such, any given author might publish both correlational and experimental studies, but use distinct terms, at least in the title, to describe these studies.

\section{Discussion and Conclusion}

This study aimed to critically evaluate the received view about the development of twentiethcentury American psychology. Using advanced text analysis tools, we quantitatively analyzed the metadata of 119,278 papers published in American psychology journals between 1920 and 1970. We extracted and analyzed the most-cited authors and the most frequently occurring title words in each of the five consecutive decades. Furthermore, we generated co-citation and cooccurrence networks in order to visually map the similarity relations between psychologists and title words as well as to analyze the development of American psychology over time.

On the basis of these analyses, we submit that there are good reasons to suppose that the standard view needs reappraising: (1) In none of the decades that we analyzed did authors who are typically classified as behaviorists belong to the most prominent (combination of) clusters. Even on a very liberal definition of behaviorism—combining the citations of all the clusters that contain authors who are commonly classified as behaviorists (clusters which often also contained Gestalt psychologists, functional psychologists, developmental psychologists, and even cognitive psychologists) - the proportion of behaviorists was never larger than a third 
of the most-cited authors in a particular decade. Moreover, in all decades analyzed, measurement of personality and mental abilities seems to be have been the main preoccupation of the field. (2) Our co-citation analyses show that the influence of behaviorism did not decline dramatically after the Second World War either (at least until 1970). Not only did the absolute number of citations to the most important behaviorists quadruple between 1940 and 1970, the share of citations to behaviorist papers also remained stable between 1940 and 1970 (approximately 28 percent of the field). (3) Finally, our analyses also challenge certain presuppositions about the development of behaviorism itself, suggesting, for example, that Skinner's work was less influential than the received view suggests.

Still, we would like to be cautious in our conclusions for both methodological and historiographical reasons. For one thing, there are several methodological limitations to the present study. First, we only analyzed two types of data: citation data and title words. There are many alternative data sources that might be useful to analyze the structure and the development of American psychology. We would be curious to see, for example, to what extent American graduate students were influenced by behaviorist approaches to psychology (e.g. by analyzing dissertations published between 1920 and 1970), to what extent behaviorism can be said to have been ideologically dominant (e.g. by studying textbook introductions to psychology between 1920 and 1970), and to what extent behaviorism played a role in American culture (e.g. by analyzing discussions about psychology outside academia).

A second methodological reason to be cautious is that our analysis is based exclusively on Web of Science data. Although our analysis of the coverage of Web of Science shows that its overall coverage is rather impressive, especially for major psychology journals, Web of Science only provides citation data for scientific articles. Since research monographs also played an important role in the development of American psychology, especially before the Second World War, our analyses do not take into account all academic output produced by 
American psychologists between 1920 and 1970. We do not have reason to presume that including data from scientific monographs would significantly affect our results, however, as our data set does include citations to research monographs. ${ }^{27}$ The only data that the present study does not analyze are the citations from research monographs. We do not have reason to believe that co-citation patterns in research monographs will paint a significantly different picture of the development of American psychology.

Second, our dataset only allowed us to construct co-citation networks on the basis of the first author of each publication. Taking co-authorship into account would have three interrelated consequences: (1) authors with a relatively large share of non-first authored publications would become more prominent in the networks, while (2) the prominence of authors with relatively few non-first authored publications would be attenuated; and (3) the distances between authors would change in ways that are difficult to predict. These are probably minor concerns, however, as single-authored papers were the norm for each of the decades under consideration. ${ }^{28}$

Third, our analysis is based on a dataset comprising all English-language psychology articles published between 1920 and 1970, whereas our primary aim is to draw conclusions about the structure and development of American psychology. It is likely that our analyses

${ }^{27}$ Indeed, research monographs such as Freud's The Interpretation of Dreams and Titchener's Teacher's Word Book belong to the most-cited documents in our data set.

${ }^{28}$ The percentages of publications by one author in the WoS dataset were $86 \%, 79 \%, 76 \%$, $66 \%$, and $55 \%$ for each of the consecutive decades. The co-citation networks were based on authors cited in these publications, but the numbers above provide a good estimate. If anything, because the co-citation analyses always 'look back', the percentage of single-authored papers in each of the networks is probably even higher. 
somewhat misrepresent the structure of American psychology if there were significant differences between American psychology and psychology in non-American English-speaking countries. It should be noted, however, that out of the top 25 journals with the most articles in our dataset (which together deliver $51 \%$ of the 119.278 articles in our catalogue), 24 are American journals. ${ }^{29}$

Most importantly, however, we would like to be cautious in drawing any major conclusions about the rise and fall of behaviorism for historiographical reasons. Rather than claiming that our analyses refute the received view that behaviorism was the dominant approach in mid-twentieth century psychology, we would prefer to use the results of our analyses to offer a broader perspective on the development of American psychology. For one thing, 'dominance' is a notoriously vague concept. Indeed, the two main measures of influence examined in the present study_citations and title terms— paint subtly different pictures about the development American psychology. Whereas our co-citation networks suggest that authors who are typically identified as behaviorists were less influential than the received view suggests, our term co-occurrence analyses reveal that behaviorist terms gradually became more prominent during the decades, thereby suggesting that behaviorist research might have played an important role in setting the direction of at least a part of psychological inquiry. And these are just two measures of 'influence'. We can only imagine what still other (conceptual,

${ }^{29}$ See Figure 1. The exception is Journal of Mental Science, which is British. We decided not to exclude articles from British journals because we have insufficient information to determine the origin of all the 246 journals in our dataset. Furthermore, it should be noted that American psychologists also often published in British psychology journals (and vice versa), such that selection at the journal level will never deliver a clean-cut distinction between American and non-American Anglophone psychology. 
sociological, educational, therapeutical, societal, or political) measures would show us about the way in which behaviorist research influenced the development of American psychology, American academia, and maybe even American society. Although Skinner's influence appears to have been limited if one solely focuses on citations, for example, it is well possible that his work (1) influenced the conceptual development of American psychology (e.g. by developing the concept of operant conditioning), (2) contributed to the technological development of American psychology (e.g. by inventing the Skinner box), and (3) impacted American society because of his frequent media interviews, his contributions to debates about the ideal society (e.g. Walden Two), and his technical inventions (e.g. the air crib and the teaching machine) (Rutherford, 2003). The story about the development of American psychology is a complex one and cannot be reduced to a single question about 'dominance'.

Second, the term 'behaviorism' itself is not a rigid, one-dimensional concept that can be defined using a fixed set of strictly delineated criteria. If anything, behaviorism is a broad collection of loosely associated psychologists and small research groups who share similar philosophical and empirical assumptions - assumptions, moreover, that changed significantly over time. For historians, it makes more sense to speak about similarities between authors, texts, and concepts, than to try to classify them using strict ahistorical categories. Indeed, the present study shows that it is perfectly possible to study the development of behaviorist research without relying on a fixed, ahistorical definition of behaviorism. In fact, our study shows that relying on similarities between authors and concepts helps us to draw richer and subtler conclusions about the development of American psychology.

Finally, and most importantly, a too narrow focus on the rise and fall of behaviorism diverts the attention away from a broader perspective on the development of American psychology. Not only do our analyses show that American psychology was more diverse than the received view suggests, they also show that the story about the development of American 
psychology is mostly a story about a rapidly expanding field of study (growing from about 6.000 publications in the 1920 s to more than 60.000 publications in the $1960 \mathrm{~s}$ ) — a story about the rise of a new and increasingly important discipline with ever broadening theoretical and applied concerns, characterized by a diversity of approaches. Our quantitative analyses, in sum, do not only help us to reappraise the standard view about the development of behaviorism, they also show us that historians need to tell both a more diverse and a more subtle story about the development of American psychology.

\section{References}

Allen, H. J. (1980). P. W. Bridgman and B. F. Skinner on Private Experience. Behaviorism, $8(1), 15-29$.

Ardilla, R. (2009). Behavior analysis in an international context. In Brock, A. C. (ed.). Internationalizing the History of Psychology (pp. 112-132). New York: New York University Press.

Baars, B. J. (1986). The Cognitive Revolution in Psychology. New York: The Guilford Press.

Bala, A., \& Gupta, B. M. (2010). Mapping of Indian neuroscience research: A scientometric analysis of research output during 1999-2008. Neurology India, 58(1), 35.

Betti, A., van den Berg, H., Oortwijn, Y., and Treijtel, C. (2019). History of Philosophy in Ones and Zeros. In Fischer, E. and Curtis, M (eds.). Methodological Advances in Experimental Philosophy (pp. 295-332). London: Bloomsbury.

Boakes, R. (1984). From Darwin to Behaviourism: Psychology and the Minds of Animals. Cambridge: Cambridge University Press.

Breland, K. and Breland, M. (1961). The Misbehavior of Organisms. American Psychologist, $16(11), 681-684$. 
Broadus, R. (1987). Toward a definition of "bibliometrics". Scientometrics, 12(5-6), 373-379. Buchanan, A. L., \& Hérubel, J. P. V. (1997). Disciplinary culture, bibliometrics, and historical studies: Preliminary observations. Behavioral \& Social Sciences Librarian, 15(2), 37 53.

Burman, J. T. (2018). Through the looking-glass: PsycINFO as an historical archive of trends in psychology. History of Psychology, 21(4), 302.

Burman, J. T., Green, C. D., \& Shanker, S. (2015). On the meanings of self-regulation: Digital Humanities in service of conceptual clarity. Child Development, 86(5), 1507-1521.

Burnham, J. C. (1968). On the Origins of Behaviorism. Journal of the History of the Behavioral Sciences, 4(2), 143-151.

Carroll, D. W. (2017). Purpose and Cognition: Edward Tolman and the Transformation of American Psychology. Cambridge: Cambridge University Press.

Chomsky, N. (1959). Review of Verbal Behavior by B. F. Skinner. Language, 35(1), 26-58.

Cohen-Cole, J. (2014). The Open Mind: Cold War Politics and the Sciences of Human Nature. Chicago: University of Chicago Press.

Coleman, S. R. (1988). Assessing Pavlov's Impact on the American Conditioning Enterprise. The Pavlovian Journal of Biological Science, 23(3), 102-106.

Cronbach, L. J. (1957). The two disciplines of scientific psychology. American Psychologist, $12,671-684$.

Cronbach, L. J. (1975). Beyond the two disciplines of scientific psychology. American Psychologist, 30, 116-127.

Day, W. F. (1983). On the Difference between Radical and Methodological Behaviorism. Behaviorism, 11(1), 89-102.

DeCarvalho, R. J. (1991). Abraham H. Maslow (1908-1970): An Intellectual Biography. Thought: Fordham University Quarterly, 66(1), 32-50. 
DeGrandpré, R. J. and Buskist, W. (2000). Behaviorism and Neobehaviorism. In Kazdin (ed.). Encyclopedia of Psychology: Volume 1 (pp. 388-393). Oxford: Oxford University Press.

Dember, W. N. (1974). Motivation and the Cognitive Revolution. American Psychologist, 29(8), 161-168.

Flis, I., \& van Eck, N. J. (2018). Framing psychology as a discipline (1950-1999): A largescale term co-occurrence analysis of scientific literature in psychology. History of Psychology, 21(4), 334.

Fuchs, A. H. and Milar, K. S. (2003). Psychology as a Science. In Freedheim, D. K. and Weiner, I. B. (eds.). Handbook of Psychology. Volume 1: History of Psychology (pp. 1-26). Hoboken, NJ: John Wiley \& Sons.

García-Pérez, M. A. (2010). Accuracy and completeness of publication and citation records in the Web of Science, PsycINFO, and Google Scholar: A case study for the computation of $\mathrm{h}$ indices in Psychology. Journal of the American Society for Information Science and Technology, 61(10), 2070-2085.

Gardner, H. (1985). The Mind's New Science: A History of the Cognitive Revolution. New York: Basic Books.

Garfield, E. (1963). Citation indexes in sociological and historical research. American Documentation, 14(4), 289-291.

Green, C. D., Feinerer, I., Burman, J. T. (2013). Beyond the Schools of Psychology 1: A Digital Analysis of Psychological Review, 1894-1903. Journal of the History of the Behavioral Sciences, 49(2), 167-189.

Greenwood, J. D. (2009). A Conceptual History of Psychology. New York: McGraw-Hill.

Guilera, G., Barrios, M., \& Gómez-Benito, J. (2013). Meta-analysis in psychology: a bibliometric study. Scientometrics, 94(3), 943-954. 
Hobbs, S. and Chiesa, M. (2011). The Myth of the Cognitive Revolution. European Journal of Behavior Analysis, 12(2), 385-394.

Hood, W., \& Wilson, C. (2001). The literature of bibliometrics, scientometrics, and informetrics. Scientometrics, 52(2), 291-314.

Joynson, R. B. (1970). The Breakdown of Modern Psychology. Bulletin of the British Psychological Society, 23(2), 261-269.

Hauser, L. (2015). Behaviorism. The Internet Encyclopedia of Philosophy, ISSN 2161-0002, http//www.iep.utm.edu/ (last accessed: February 2019).

Hergenhahn, B. R. (2005). An Introduction to the History of Psychology. $6^{\text {th }}$ edition. Belmon, CA: Wadsworth.

Lashley, K . S. (1951). The Problem of Serial Order in Behavior. In Jeffress, L. (ed.). Cerebral Mechanisms in Behavior. New York: Wiley.

Leahey, T. H. (2001). A History of Modern Psychology. $3^{\text {rd }}$ edition. Upper Saddle River, NJ: Prentice-Hall.

Lee, W. (2008). How to identify emerging research fields using scientometrics: An example in the field of Information Security. Scientometrics, 76(3), 503-525.

Liao, P. C., Zhang, K., Wang, T., \& Wang, Y. (2016). Integrating bibliometrics and roadmapping: A case of strategic promotion for the ground source heat pump in China. Renewable and Sustainable Energy Reviews, 57, 292-301.

Liu, S., \& Oakland, T. (2016). The emergence and evolution of school psychology literature: A scientometric analysis from 1907 through 2014. School Psychology Quarterly, 31(1), 104.

López-Cózar, E. D., Orduna-Malea, E., \& Martín-Martín, A. (forthcoming). Google Scholar as a data source for research assessment. In Glänzel, W., Moed, H.F., Schmoch, U., Thelwall, 
M. (Eds.). Springer Handbook of Science and Technology Indicators. Heidelberg, Germany: Springer.

Mandler, G. (2002). Origins of the Cognitive (R)evolution. Journal of the History of the Behavioral Sciences, 38(4), 339-353.

Martínez-Gómez, A. (2015). Bibliometrics as a tool to map uncharted territory: A study on non-professional interpreting. Perspectives, 23(2), 205-222.

Mills, J. A. (2012). Behaviorism. In Rieber, R. W. (ed.). Encyclopedia of the History of Psychological Theories (pp. 98-110). New York: Springer.

Moore, J. (1981). On the Principle of Operationism in a Science of Behavior. Behaviorism, 3(2), 120-138.

O’Donnell, J. M. (1985). The Origins of Behaviorism: American Psychology, 1870-1920. New York: New York University Press.

O’Donohue, W. T. and Kitchener, R. F. (1999a, eds.). Handbook of Behaviorism. London: Academic Press.

O'Donohue, W. T. and Kitchener, R. F. (1999b). Introduction: The Behaviorisms. In O’Donohue and Kitchener (1999a), pp. 1-13.

Orduña-Malea, E., \& López-Cózar, E. D. (2014). Google Scholar Metrics evolution: an analysis according to languages. Scientometrics, 98(3), 2353-2367.

Parot, F. (2001). Behaviorism, History of. In Smelser, N. J. and Baltes, P. B. (eds.). International Encyclopedia of the Social \& Behavioral Sciences: Volume 2 (pp. 11311137). Oxford: Elsevier.

Pavlov, I. P. (1923/1928). Lectures on Conditioned Reflexes: Twenty-Five Years of Objective Study of the Higher Nervous Activity (Behaviour) of Animals. Translation by W. H. Gantt. New York: international Publishers. 
Pooley, J. \& Solovey, M. (2010). Marginal to the Revolution: The Curious Relationship between Economics and the Behavioral Sciences Movement in Mid-TwentiethCentury America. History of Political Economy, 42(Suppl_1), 199-233.

Ringen, J. (1999). Radical Behaviorism: B. F. Skinner's Philosophy of Science. In O’Donohue and Kitchener (1999a), pp. 159-178.

Robins, R. W., Gosling, S. D., \& Craik, K. H. (1999). An empirical analysis of trends in psychology. American Psychologist, 54(2), 117.

Roediger III, H. L. (2004). What happened to behaviorism. APS Observer, 17(3), 40-42.

Rutherford, A. (2003). B.F. Skinner's technology of behavior in American life: From consumer culture to counterculture. The History of Behavioral Sciences, 39(1), 1-23.

Samelson, F. (1981). Struggle for Scientific Authority: The Reception of Watson's Behaviorism, 1913-1920. Journal of the History of Behavioral Sciences, 17(3), 399425.

Schui, G., \& Krampen, G. (2010). Bibliometric analyses on the emergence and present growth of positive psychology. Applied Psychology: Health and Well-Being, 2(1), 52-64.

Sechenov, I. M. (1863/1965). Reflexes of the Brain. Cambridge, MA: M.I.T. Press.

Skinner, B. F. (1945a). The Operational Analysis of Psychology Terms. Psychological Review, 52(5), 270-277.

Skinner, B. F. (1945b). Rejoinders and Second Thoughts, B. F. Skinner. Psychological Review, $52(5), 291-294$.

Skinner, B. F. (1974). About Behaviorism. New York: Alfred A. Knopf.

Small, H. (1973). Co-citation in the scientific literature: a new measure of the relationship between two documents. Journal of the American Society for Information Science, 24, 265-269. 
Smith, L. D. (1986). Behaviorism and Logical Positivism: A Reassessment of the Alliance. Stanford: Stanford University Press.

Staddon, J. E. R. (1999). Theoretical Behaviorism. In O’Donohue and Kitchener (1999a), pp. $217-41$.

Todd, J. T. (1994). What Psychology Has to Say About John B. Watson: Classical Behaviorism in Psychology Textbooks, 1920-1989. In Todd, J. T. and Morris, E. K. (eds). Modern Perspectives on John B. Watson and Classical Behaviorism (pp. 75-108). Westport, CT: Greenwoord Press.

Thompson, D. F., \& Walker, C. K. (2015). A descriptive and historical review of bibliometrics with applications to medical sciences. Pharmacotherapy: The Journal of Human Pharmacology and Drug Therapy, 35(6), 551-559.

Van Eck, N. J., \& Waltman, L. (2010). Software survey: VOSviewer, a computer program for bibliometric mapping. Scientometrics, 84(2), 523-538.

Van Eck, N. J., \& Waltman, L. (2009). How to normalize cooccurrence data? An analysis of some well-known similarity measures. Journal of the American Society for Information Science and Technology, 60(8), 1635-1651.

Verhaegh, S. (2019). The behaviorisms of Skinner and Quine: Genesis, development, and mutual influence. Journal of the History of Philosophy, 57(4), 707-730.

Verhaegh, S. (ms.). Who started the 'revolution'? The divergent origins of operationism in psychology.

Walter, M. L. (1990). Science and Cultural Crisis: An Intellectual Biography of Percy Williams Bridgman (1882-1961). Stanford: Stanford University Press.

Waltman, L., Van Eck, N. J., \& Noyons, E. C. (2010). A unified approach to mapping and clustering of bibliometric networks. Journal of Informetrics, 4(4), 629-635. 
Watson, J. B. (1913). Psychology as the Behaviorist Views It. Psychological Review, 20(2), $158-177$.

Zuriff, G. E. (1985). Behaviorism: A Conceptual Reconstruction. New York: Columbia University Press. 